\title{
Brexit and The Impact of Gradual Economic Integration on Export
}

Rutger Teulings ${ }^{1}$ 
Tinbergen Institute is the graduate school and research institute in economics of Erasmus University Rotterdam, the University of Amsterdam and VU University Amsterdam.

Contact: discussionpapers@tinbergen.nl

More TI discussion papers can be downloaded at the Tinbergen Site

Tinbergen Institute has two locations:

Tinbergen Institute Amsterdam

Gustav Mahlerplein 117

1082 MS Amsterdam

The Netherlands

Tel.: +31(0)20 5984580

Tinbergen Institute Rotterdam

Burg. Oudlaan 50

3062 PA Rotterdam

The Netherlands

Tel.: +31(0)10408 8900 


\title{
Brexit and the impact of gradual economic integration on export
}

\author{
Rutger Teulings * \\ University of Amsterdam and Tinbergen Institute
}

August 2, 2017

\begin{abstract}
I develop an index for economic integration accounting for its gradual and bilateral nature: the Gradual And Bilateral Integration (GABI) index. The graduality captures differences in the depth and path of five stages in economic integration and is an improvement over the use of binary dummy variables. Its bilateral nature allows for country-pair differences, which is not possible with the multilateral indexes in existing literature. I apply the GABI index to a gravity model for 18 OECD countries and estimate the impact of the five stages on export. The estimates for these five stages allow me to investigate four different Brexit scenarios in a general equilibrium analysis, ranging from soft to very hard Brexit. I find that in the latter scenario real export of the UK decreases by a significant $32 \%$ in the long run. Other EU countries also experience a decrease in real export, while non-EU countries experience an increase due to trade diversion effects. Similarly, I also investigate potential future free trade agreements like TTIP.
\end{abstract}

Key words: Balassa stages, economic integration, gravity model, Brexit, TTIP.

JEL classification: F13; F14; F15.

\footnotetext{
${ }^{*}$ Contact details. Address: Amsterdam School of Economics, PO Box 15867, 1001 NJ Amsterdam, The Netherlands; tel. +31-20-5254157; e-mail: r.m.teulings@uva.nl.

I would like to thank Maurice Bun, Franc Klaassen and Yoto Yotov for their constructive feedback and useful discussions helping to improve the paper. Furthermore, I would like to thank Ismael Valdes and Alfred Yong Chai Yee for their extensive work on the economic integration index.

This paper is based on my MPhil thesis "The impact of gradual trade liberalization on export".
} 


\section{Introduction}

Economic integration is a time consuming process, it has a long path, and it differs in depth across country-pairs. The most common way to estimate the effect of economic integration agreements (EIA) on bilateral exports is by using bilateral dummy variables, turning to one when economic integration commences and irrespective of how deep the progress will go.

Dorrucci et al. (2005) has constructed a multilateral gradual integration index for the EU-6 ${ }^{1}$, henceforth indicated by the ECB index. This index splits up EIAs into smaller events. Each event is categorized into one of the five stages of economic integration, as defined by Balassa (1961), and gets weights assigned to based on the contribution to the specific stage and total economic integration in general for all EU-6 countries combined. In this way it accounts for the depth and path of EIAs improving upon the binary dummy approach. However, the dummies are bilateral and can account for differences in economic integration across country-pairs.

This paper proposes an alternative method. I construct a Gradual And Bilateral Integration (GABI) index, based on the ECB index. The gradual aspect improves upon the dummy variable and the bilateral aspect improves upon the ECB index. So, I account for path and depth and differences across partners. The GABI index has four advantages. First, the gradual aspect of the GABI index allows me to distinguish the differences in depth and path of EIA. Second, it can identify all the different EIA because the corresponding indexes reflect the differences in depth and path per EIA, leading to more variation and less correlation between the respective variables. If one captures all these EIAs by just adding more dummies they will start to overlap because they are only zero or one, potentially causing multicollinearity. Hence, dummy variables cannot be added indefinitely to capture EIAs. This important property is used to analyse the impact of Brexit later on. Third, the gradual aspect allows for the identification of the dynamic impact of economic integration because lags no longer also capture the gradual aspect of EIA. Finally, the bilateral aspect of the GABI index captures country-pair differences allowing me to use it as independent variable in explaining bilateral exports, which is not possible with the multilateral ECB index.

There is a wide literature on the impact of economic integration on exports. Tinbergen (1962) is one of the first to study the impact of EIAs and in particular FTAs on exports, by including among others an FTA dummy variable. He does not find a significant effect. Today, the mainstream view in the economic literature is that eco-

\footnotetext{
${ }^{1}$ Belgium, France, Germany, Italy, Luxembourg and the Netherlands
} 
nomic integration increases exports. In turn increasing exports increases GDP and therefore welfare ${ }^{2}$. Among others, Baier \& Bergstrand (2007), henceforth abbreviated as BB2007, use a panel data model to show that bilateral exports of two FTA members doubles after 10 years, where they use a dummy variable for countries that sign an FTA and include lags to capture the phase-in. Roy (2010) distinguishes between an FTA and a custom union (CU) dummy and finds that the CU is actually responsible for the doubling of exports. Baier and Bergstrand further distinguish between 7 different levels of economic integration in their multichotomous index (see Bergstrand's website http://www.nd.edu/jbergstr). Baier et al. (2014) use this index and find that economic integration doubles trade and an FTA increases trade by $60 \%$. Cipollina \& Salvatici (2010) show in their meta-analysis of 85 papers that the estimated impact on exports of economic integration ranges between $12 \%$ and $285 \%$ a median of $46 \%$. Dür et al. (2014) have an extensive study of different type of economic integration agreements. They remark the importance of the difference in depth of these agreements. They develop a measure that varies in a discrete manner between 0 and 7 . They also constructed a similar measure using a latent trait analysis. Egger \& Tarlea (2017) uses dummy variables to capture four different depths in FTAs. They also account for bilateral investment treaties and double-tax treaties using dummies. However, one cannot indefinitely add dummies because this will lead to multicollinearity problems at some point. The GABI index does not suffer from this problem. Badinger (2005) uses a different approach. He develops a multilateral integration index for the EU that is based on tariff reductions, capturing gradual economic integration, similar to the ECB index. However, unlike the ECB index, he cannot account for EIAs that do not involve tariff reductions.

As a framework for my empirical model I will use the extended real gravity model by Klaassen \& Teulings (2015a). The empirical model is applied to the export data of 18 OECD countries.

The empirical model is used to compare the estimated impact of dummy variables capturing economic integration and GABI index. The results clearly display the two advantages of using the GABI indexes over dummy variables, as discussed above. Depending on the estimation method, I find that aggregate of all five economic integration stages increases exports between $35 \%$ and $108 \%$.

Because it is now possible to obtain reliable estimates for the five different economic integration stages using the GABI index, I can now use these estimates to evaluate

\footnotetext{
${ }^{2}$ There are also disadvantages to economic integration, such as trade diversion. I will elaborate further on these disadvantages in Section 2.1.
} 
different Brexit scenarios, i.e. the UK leaving the EU. To that end I use a general equilibrium (GE) analysis proposed by Anderson et al. (2015). The results show that UK loses by far the most from Brexit in terms of exports, depending on the scenario real exports decreases with $2-32 \%$, where the worst case scenario leads to the biggest lose in exports. But also for other EU countries exports decreases as a consequence of Brexit, especially Ireland for which real export decreases with $1-10 \%$. Non-EU countries mostly gain from Brexit, although the effects are small, due to the principle of trade diversion, as proposed by Viner (1950), increasing real export with $0-1.2 \%$. In terms of real GDP it is not the UK that loses the most but Ireland, depending on the scenario it loses between $0.4-1.4 \%$.

The remainder of this paper is setup as follows. Section 2 discusses how to construct the GABI index. Next, Section 3 discusses the empirical model based on the theoretical gravity model and describes the data. Section 4 displays the estimation results for the impact of the GABI indexes. The estimation results are used in Section 5 to perform a GE analysis investigating different Brexit scenarios, the Transatlantic Trade and Investment Partnership (TTIP) and the Comprehensive Economic and Trade Agreement (CETA). In Section 6 I perform two robustness checks. Finally, Section 7 concludes.

\section{Economic integration}

In this section I discuss the theoretical merits and costs of economic integration. Next, I discuss the five stages of economic integration as proposed by Balassa (1961). Finally, I explain how Dorrucci et al. (2005) construct the regional index based on these five stages and how I extend and further improve this to the GABI index.

\section{$2.1 \quad$ Theoretical views}

Economic integration is when two or more countries are unifying economic policies, like fiscal, trade, monetary, and social economic policies. The motivation for economic integration can be both economical as well as political.

The main economic motivation is to increase welfare in all participating countries by allowing goods, services and production factors freely move between countries. This is done by taking away both tariffs and non-tariff barriers (NTB), opening up foreign markets and making trade worthwhile. Viner (1950) calls this trade creation and shows that this by itself has a positive effect on welfare.

There are also other mechanisms that induce welfare gains from trade. The HeckscherOhlin model (Heckscher (1919) and Ohlin (1933)) explain the gains from trade with 
comparative advantage. A country with a comparative advantage in a certain good produces this good relatively more efficient than other countries and this leads to specialization if trade is liberalized. This leads to welfare gains. Krugman $(1979,1980)$ introduces economies of scale for firms to explain trade. The opening up of foreign markets leads to a larger market and gives firms opportunity to improve their economies of scale. Gains from trade arise because consumers want to consume as many varieties as possible, so called love of variety, and liberalizing trade implies better access to more varieties increasing consumer's utility. Rivera-Batiz \& Romer (1991), among others, argue that economic integration extends the market and therefore leads to an endogenous rise in economic growth, due to economies of scale. On a micro level Melitz (2003) shows that firm heterogeneity matters. Trade liberalization increases intra industry trade leading to a reallocation of resources to the more productive firms and increasing the aggregate industry productivity. This leads to welfare gains. See Redding (2011) for a good literature overview on firm heterogeneity in trade.

Economic integration can also make further economic integration efficient. The main example is the optimum currency area theory introduced by Mundell (1961). Only if countries are sufficiently integrated, for example having sufficient labor and capital mobility between countries, is it efficient to introduce a single currency.

The main political motivation for economic integration is that it is considered to be the first step to a stable political union. For example, in 1951 the European Coal and Steel Community (ECSC), the predecessor of the EU, was founded. The main goal of the ECSC was preventing any future wars, like World War I and II, from happening again in Europe by enforcing cooperation in the two most important resources for the defense industry.

However, economic integration between countries also has its drawbacks. The reduction of trade barriers among participating countries and possibly implementing common trade barriers towards non-participating countries leads to trade diversion (Viner (1950)). If two partner countries, say, the Netherlands and Germany, liberalize trade, it becomes cheaper for the Netherlands to import, say, cars from Germany instead of importing it from a third more or equally efficient car-producing non-participating country. Hence, the more efficient industry loses market share to a less efficient industry leading to a decrease in the formers welfare. At the same time the Netherlands receives less income from import tariffs reducing its welfare.

Economic integration can also lead to unemployment in the partner-country with the relatively least productive industry, because this industry might be forced to close down due to increasing competition. Economic integration is overall welfare increasing, 
but there are countries that gain and countries that lose from economic integration and only by redistributing the welfare gains it can be ensured that all countries gain from economic integration. In practice this is often difficult to realize, offering an important argument for protectionism, refraining from (further) economic integration.

Finally, the currently most topical drawback of economic integration is that the bigger the depth of economic integration the more sovereignty, concerning legislation, monetary and fiscal policy et cetera, the individual countries lose. Recently, this has led to increasing economic and political tension in the EU, giving rise to strong anti-EU movements in almost all EU member states.

Overall, non-participating countries always lose from economic integration, while participating countries might gain or lose depending on whether the advantages outweigh the disadvantages or not. Badinger $(2005,2008)$ shows that economic integration in the EU increases the level of GDP by $25-44 \%$. However, he does not find a long-run relation.

For further reading on economic integration in general and that of the EU in specific see Baldwin \& Wyplosz (2015).

\subsection{The Balassa stages}

Balassa (1961) divides economic integration into five stages, henceforth called Balassa stages, where each subsequent stage is deepening the integration; so the stages are cumulative. For example, if a group of countries reached stage 2 they automatically reached stage 1 as well. The Balassa stages are:

FTA Free trade agreement: all member states abolish trade tariffs and import quotas for goods and services with respect to other member states. Each member state maintains its own trade barrier policies regarding non-member states. NTBs can still prevent perfect free trade.

$C U$ Custom union: an FTA, where in addition all members have uniform trade barrier policies regarding non-member states.

CM Common market: a CU, where all other NTBs on export and restrictions on factor movements between member states are abandoned and a common policy regarding non-member states.

EUN Economic union: a CM, with advanced cooperation concerning economic policies and standardization of relevant national laws. 
TEI Total economic integration: a EUN, where all relevant economic policies, such as monetary and fiscal policies, are arranged at a supranational level. To enforce these policies supranational authorities and laws are installed.

\subsubsection{Application to the EU}

The EU's economic integration history is a good example for the Balassa stages. In 1951 the EU-6 signed the treaty of Paris founding the European Coal and Steal Community (ECSC). In 1957 the ECSC was extended with the rectification of the treaty of Rome. This added, next to the political goal of peace and stability, the economic goal of trade liberalization. In 1968 both the FTA and CU were completed.

In the Schengen Agreement in 1985 the member states agreed to abolish all borders between the participating countries, although the actual implementation is more than 10 years later. With the Single European Act (SEA) in 1986 the member states agreed to reach a single market by the end of 1992, further abolishing NTBs. These two agreements were a major step towards a CM. In the same period the EU was extended with new members. Table C.1 displays all the EU-15 $5^{3}$ entry dates.

The foundations for an EUN were already laid down with the treaty of Rome, starting to unify national laws and economic policies. Over time this was developed further. The treaty of Maastricht in 1992 arranged, among others, a staged plan towards a single currency and further unified national laws, economic and monetary policies, an important step towards EUN and TEI. In 1999 the Euro became the common currency in eleven EU countries ${ }^{4}$. Greece joined in 2001.

In the next 12 years the treaty of Amsterdam, Nice and Lisbon were signed to reform the EU's institutional structure contributing further to TEI and making future extension of its members possible, especially towards Eastern Europe.

Important future steps towards TEI are: more labor mobility, extending unification of the European capital market and aligning national structural and macroeconomic policies.

\subsection{Constructing the Gradual And Bilateral Integration index}

I use the constructed ECB index by Dorrucci et al. (2005) to construct a Gradual And Bilateral Integration (GABI) index that measures the depth and path of economic in-

\footnotetext{
${ }^{3}$ This are all EU countries before the May 2004 expansion: Belgium, France, Germany, Italy, Luxembourg, Netherlands, Denmark, Ireland, United Kingdom, Greece, Portugal, Spain, Austria, Finland and Sweden.

${ }^{4}$ Belgium, France, Germany, Italy, Luxembourg, Netherlands, Ireland, Portugal, Spain, Austria and Finland.
} 
tegration. First, I describe how the ECB index is constructed and measure multilateral economic integration in the EU-15. Next, I explain how I extend this data set and how I use it to create a bilateral GABI index.

\subsubsection{The ECB index: multilateral economic integration}

Dorrucci et al. (2002) construct the multilateral ECB index from 1957-2001 for the EU-6 as a whole. Later on Dorrucci et al. (2005) specify the multilateral economic integration for each of the EU-6 separately and extend the data-set by including the remaining EU-15 countries. This partly involves the development within the EFTA and EEA. ${ }^{5}$

The main idea of the multilateral ECB index is to divide the complete economic integration into smaller events. Subsequently, each event is categorized into one of the five Balassa stages and gets points assigned representing its contribution to the specific stage. Events only receive points if they implement an EIA, while only signing a new agreement to implement new EIA in the future gets zero points. For example, the initial Schengen agreement is signed in 1985, while the actual abolishment of border controls becomes only affective in 1995. Therefore, the former gets 0 points and the latter gets 1 point.

Together all events in a Balassa stage have a maximum of 25 points, with the exception of the FTA and CU stages, they get assigned 15 and 10 points, respectively. So, countries that complete economic integration get 100 points, while countries in autarky get 0 points. The point distribution for each of the five stages is only given for the EU-6 as a hole. For all the 15 countries separately, they only report the total number of points for all stages combined.

The assigning of points to different events allows for the distinction in the difference of depth and path in EIA. Still, the distribution of points is subjective, regarding both the number of points for a single event as well as the distribution of points over the five stages. For some measures, like the abolishing of trade tariffs, the assigning of points can be done in a relative objective way because tariffs are reduced in percentages and the reduction steps are therefore comparable. For other more abstract measures, like abolishing border controls, it is hard to define their individual contribution and mutually compare their contribution. However, dummy variables are even more subjective because they capture EIA with different depths and paths with a binary variable. The

\footnotetext{
${ }^{5}$ Dorrucci et al. (2015) append the regional index by including the development and changes of the Economic and Monetary Union (EMU) as a consequence of the financial and euro area crisis. This new index allows for even deeper economic integration. However, since my data only goes up to $2011 \mathrm{I}$ will refrain from using this updated index.
} 
researcher has to determine when he lets the dummy variable switch to one, at the beginning, halfway or at the end of reaching, say, a FTA and whether he treats all EIA identical, even though they vary in depth and path, or that he leaves out the more shallow EIA.

The contribution of the ECB index is twofold. First, it allows for the comparison of the difference in depth and path of economic integration between different regions and Balassa stages, while binary dummy variables do not allow for this distinction. Second, it allows for the identification of the impact of EIA between different regions, Balassa stages and the dynamic impact of EIA, while binary dummy variable cannot identify all these different aspects at the same time because the largely overlap causing potential multicollinearity problems between the different dummy variables. The ECB index has one disadvantage, it is time consuming to construct compared to a dummy variable.

The five stages in the ECB index can develop in parallel, which is opposite to the Balassa stage, where the stages develop in progressive order. Furthermore, the stages in the ECB index measure only the additional contribution to economic integration, whereas the Balassa stages are cumulative. I indicate the incremental nature of the stages with a + in the superscript.

Figure 1: Different multilateral economic integration measures

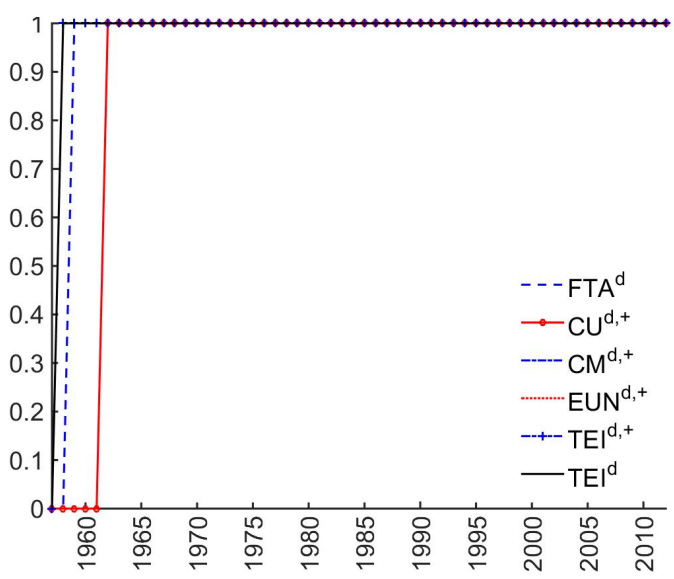

(a) Multilateral dummies for the EU-6.

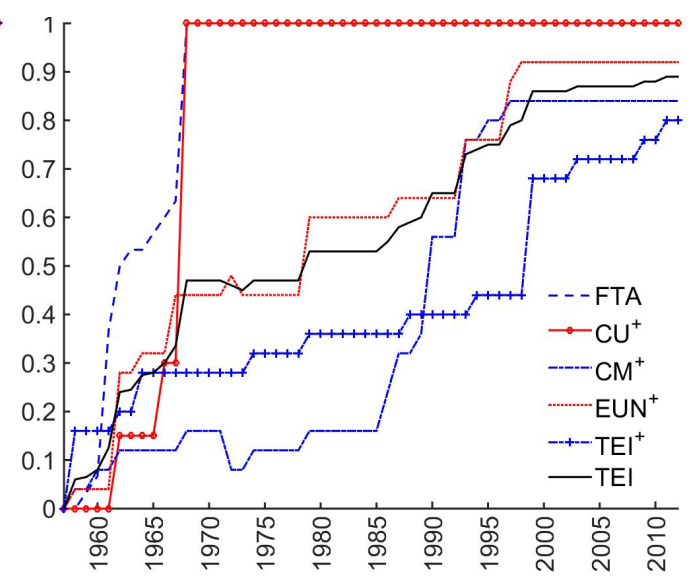

(b) Multilateral ECB index for the EU-6.

In Figure 1a I display the multilateral EIA dummies for all five Balassa stages for the EU-6, where the $d$ in the superscript indicates that the variables are dummies. All five dummy variables switch to one if economic integration commences in the respective stages. I also construct the Total Economic Integration (TEI) dummy that aggregates 
all five stages together. There is no distinction between differences in depth and path of economic integration. Furthermore, it is clearly visible that the dummy variables overlap and therefore potentially suffer from multicollinearity.

In Figure 1b I display the five stages of the multilateral ECB index and the TEI index for the EU-6, where I normalize all six variables to one by dividing them by the maximum number of points possible per variable. The development of the five stages is in correspondence with EU's economic integration history, see Section 2.2.1. The FTA and $C U^{+}$reach one in 1968 . The $C M^{+}$starts to rapidly increase by implementing the SEA directives after signing the SEA in 1986. Starting with the treaty of Rome, $E U N^{+}$and $\mathrm{TEI}^{+}$slowly develop over time, due to standardization of national laws and arranging economic policies on a supranational level. The small dip in $E U N^{+}$are because of the collapse of Bretton Woods in the early seventies. The implementation of the euro causes $\mathrm{TEI}^{+}$to increase rapidly in 1999. In 20011 the EU-6 has a total of 89 points out of 100 . The two advantages of the regional index are clearly visible, comparing it to the dummy variables. It is possible to have different depths and paths of economic integration and to identify the five stages separately.

\subsubsection{Extending the ECB index}

The ECB index is updated and extended by me in three ways. First, based on the original treaties ${ }^{6}$ I determine for each EU-15 country separately to which of the five stages their points must be assigned, similar to the EU-6 as a whole in Dorrucci et al. (2005). Hereby, I use their proposed distribution of points over the five stages. ${ }^{7}$

Second, I extend the data-set to 2011 and update and extend the events based on the original treaties, making the accession of, say, Greece to the EU even more gradual.

Finally, I extend the data set by including the separate multilateral development of CUSFTA and NAFTA, where I include the CUSFTA countries Canada and the USA, and I include two additional EFTA members Norway and Switzerland and. ${ }^{8}$ Japan is also added to the data set but no EIA is assigned to Japan with respect to any other countries in the data set. ${ }^{9}$

Future extensions of the ECB index can be to include even more details of all the EIA making it even more gradual, extend the ECB index to incorporate other countries

\footnotetext{
${ }^{6}$ http://eur-lex.europa.eu contains the different accession treaties of new member-states.

${ }^{7}$ see Table A1.1 and A1.2 in their appendix for an extensive description

${ }^{8}$ The newly added events are constructed with information from various sources, such as the EU, EFTA, EEA, World Trade Organization, International Monetary Funds (IMF), Ministries of Trade and International Labor organizations.

${ }^{9}$ The FTA, signed in 2010, between Japan and Switzerland is not jet incorporated in the ECB index.
} 
and including multilateral treaties such as the General Agreement on Tariffs and Trade (GATT). We will leave this for future research.

\subsubsection{The GABI index: bilateral economic integration}

To construct the GABI index from the extended multilateral ECB index I have to take into account that a country can sign an EIA with respect to a different set of countries. For example, if in 1959 the UK joins the EFTA it engage in economic integration with respect to all EFTA members, but when in 1973 the UK joins the EU-6 it engage in economic integration with respect to the EU-6. So, I cannot simply add these two EIA to obtain UK's total economic integration, because the EIAs are signed with respect to two different set of countries. So, I have to keep track with respect to what set of countries a country signs an EIA. Furthermore, it is not enough to simply keep track of which countries join the EU. For each EIA event one has to keep track which country signed it and which did not taking into account that countries can enter or leave at a later period in time. For example, when Greece enters the EU in 1981 it does not join the European Monetary System (EMS). So, when Spain joins the EMS in 1989 it does not get points with respect to Greece, even though Greece entered the EU like Spain. Only when Greece enters the EMS in 1998, Greece gets the assigned points with respect to all other EMS countries. By careful bookkeeping we can construct a GABI index.

Figure 2: Total economic integration: multilateral versus bilateral

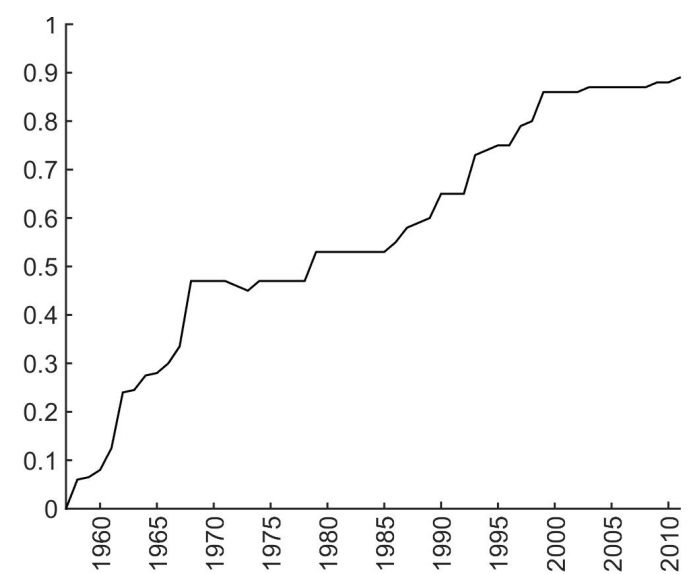

(a) Multilateral TEI of the EU-6.

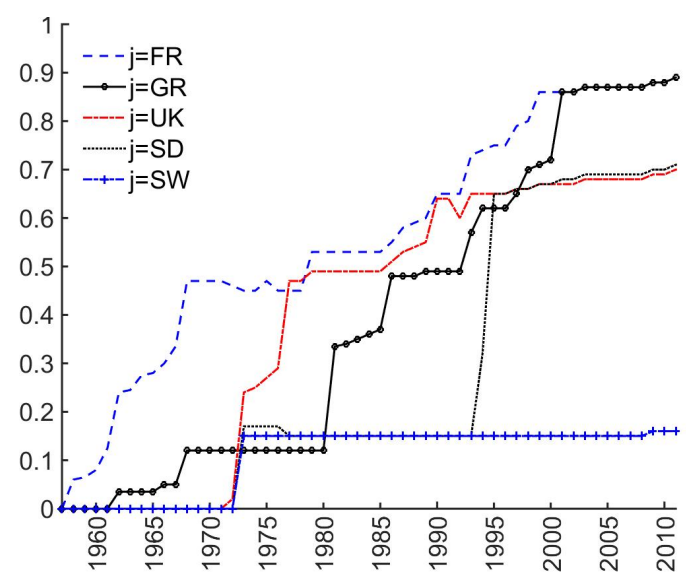

(b) Bilateral $T E I_{i j t}$ for Germany $i-j$.

To exemplify the importance to go from unilateral to bilateral, I compare Figure $2 \mathrm{a}$ with Figure 2b. The former displays the multilateral TEI of the EU-6 in, the 
same as that in Figure 1b. The latter displays $T E I_{i j t}$ between Germany and five different countries: France (FR), Greece (GR), United Kingdom (UK), Sweden (SD) and Switzerland (SW), where again all five $T E I_{i j t}$ are normalized by dividing them by the maximum number of points (100). By making the ECB index bilateral, each country-pair has a different depth and path of $T E I_{i j t}$, while the multilateral ECB index can only capture TEI for the EU-6 as a whole. Not only is this possible for $T E I_{i j t}$, the aggregate of the five Balassa stages, but for all five Balassa stages separately as well.

If I capture the five $T E I_{i j t}$ series in Figure $2 \mathrm{~b}$ with dummy variables, I can no longer distinguish between the differences in depth and path between the countrypairs. Furthermore, I have to make a subjective choice when the dummy switches to one, for example at the beginning of economic integration or after passing a certain threshold. If I chose, say, the former then I will not be able to distinguish the countrypairs BD-SD from BD-SW and BD-UK will also be very similar. This exemplifies the advantages of the GABI index over bilateral dummy variables.

\section{Empirical approach}

In this section I will shortly describe the theoretical gravity model that I use both as a starting point for my empirical model, that I describe next, and in the GE analysis of Brexit, TTIP and CETA. I will elaborate on the estimation method and potential endogeneity in the empirical model. Finally, I will discuss the data.

\subsection{The theoretical gravity model}

The gravity model explains bilateral export with the basic idea that the larger two countries are in economic terms the more they trade, where economic size is measured by GDP. However, the further two countries are apart the less they trade. This can be both physical and economic distance, for instance high bilateral tariff rate between two countries. This is called the bilateral trade barrier.

Tinbergen (1962) is one of the first to use the gravity model to analyze trade flows, since that time the model is used as a workhorse model in trade literature. Although its theoretical motivation was missing in the beginning, its explanatory power was evident. Anderson (1979) and Bergstrand (1985) are one of the first who give a theoretical justification for the gravity model. Recently Anderson \& van Wincoop (2003) make an important contribution. They introduce the notion of multilateral export and import resistance, measuring the weighted resistance to export and import respectively. Now it is the bilateral trade barrier relative to the weighted trade barrier with respect to 
the rest of the world (RoW) that matters for bilateral export and not only the bilateral trade barrier itself. For example, if the RoW is relatively far away from these two countries, then it becomes for them relatively cheaper to import from each other than from the RoW. This paper gave a boost to the theoretical gravity literature and since then various extensions and new insights are published.

In this paper I will use a recent extension by Klaassen \& Teulings (2015a). They introduce the exchange rate into the nominal gravity model and show how to rewrite this into a real gravity model. Introducing the exchange rate has three advantages. First, the exchange rate is important in explaining export. If the currency of the exporter decreases, its goods become cheaper for the importing country leading to more exports. Second, it also introduces the effective exchange rate of both the exporter and importer through the multilateral resistance (MR) terms. If the effective exchange rate of, say, the exporter depreciates vis-á-vis the RoW its good becomes cheaper for the RoW leading to more demand and thus higher prices for its good and this crowds out import by the importer. Finally, the exchange rate ensures that the currency dimensions on both the left- and right-hand-side are the same.

The nominal gravity equation starts from the standard consumer problem keeping in mind the different currency dimensions of all nominal variables. They obtain an export demand equation that describes the nominal value of export from the exporter $i$ to the importer $j$

$$
X_{i j}^{j}=w_{i}^{y}\left(\frac{b_{i j} / S_{i j}}{\Pi_{i} P_{j}}\right)^{1-\sigma} E_{j}
$$

where the $j$ superscript denotes that $X_{i j}^{j}$ is in $j$ currency, $w_{i}^{y}$ is the weight of exporter income in total world income, $b_{i j}$ is the bilateral trade barrier, $S_{i j}$ is the nominal exchange rate defined as the amount of $i$ currency one has to pay to obtain one unit of $j$ currency, $\sigma$ is the elasticity of substitution that is typically assumed to be bigger than 1 and $E_{j}$ is the expenditure of country $j$. Finally, the export demand equation is subject to $\Pi_{i}$ and $P_{j}$, the producer and consumer MR respectively,

$$
\begin{aligned}
\Pi_{i} & =\left(\sum_{j}\left(\frac{b_{i j} / S_{i j}}{P_{j}}\right)^{1-\sigma} w_{j}^{e}\right)^{\frac{1}{1-\sigma}}, \\
P_{j} & =\left(\sum_{i}\left(\frac{b_{i j} / S_{i j}}{\Pi_{i}}\right)^{1-\sigma} w_{i}^{y}\right)^{\frac{1}{1-\sigma}},
\end{aligned}
$$

where $w_{j}^{e}$ is the weight of importer expenditure in total world expenditure. The supplier MR measures the competitiveness of the exporting country, the higher the lower 
its competitiveness. The consumer MR measures the consumer price index of the importing country.

Klaassen \& Teulings (2015a) rewrite the nominal equation into a real gravity equation using the price index as a deflator. This results into the following demand equation for the quantity of export from the exporter $i$ by the importer $j$

$$
x_{i j}=\left(\frac{w_{i}^{y}}{\lambda_{i}}\right)^{\frac{-1}{1-\sigma}} w_{i}^{y}\left(\frac{b_{i j}}{s_{i j} \pi_{i}}\right)^{-\sigma} c_{j},
$$

where $\lambda_{i}$ is the taste parameters for the good of country $i$ and $j$ respectively (the higher $\lambda_{i}$ the more consumers favour good $\left.i\right), s_{i j}$ is the real exchange rate (RER) and $c_{j}$ is aggregate consumption index of country $j$. Note that real variables have lowercase symbols. Finally, the real export demand equation is subject to the real supplier MR of country $i \pi_{i}$

$$
\pi_{i}=\left[\sum_{j}\left(\frac{b_{i j}}{s_{i j}}\right)^{1-\sigma} w_{j}^{e}\right]^{\frac{1}{1-\sigma}},
$$

where $\pi_{j}$ is similar to $\pi_{i}$ and $w_{j i}^{x}$ is the weight of bilateral export of country $j$ to $i$ in total export by country $j$.

There are two striking difference between the real and the nominal model. The first difference is the additional term on the right-hand-side $\left(\frac{w_{i}^{y}}{\lambda_{i}}\right)^{\frac{-1}{1-\sigma}}$. If the taste parameter of good $i$ increases, good $i$ becomes more popular in the RoW increasing the price for good $i$. Consequently, country $j$ can consume less of good $i$. If the weighted output of country $i$ increases, good $i$ is supplied more abundant decreasing the price for good $i$. Consequently, country $j$ can consume more of good $i$. The second difference is that the consumer price index of the importer no longer plays a role.

\subsection{The empirical model and estimation}

I will use a three dimensional FE panel data model approach to model the real gravity equation, where I include a time dimension $t$ as the additional third dimension. BB2007 and Egger (2000) show that FE are preferred over random effects. Just as Klaassen \& Teulings (2015a) I will consider a log-linearized version of the real gravity model (4) subject to (5). I will add multiple FE-types to capture most source of unobserved heterogeneity. To prevent multicollinearity between all these FE-types, I use the untangling normalization method as introduced in Klaassen \& Teulings (2015b) and as extended to a three dimensional panel data model in Klaassen \& Teulings (2015a). 
Hence, the benchmark empirical model becomes

$$
\exp _{i j t}=G A B I_{i j t}^{\prime} \beta+\alpha+\alpha_{i}^{x}+\alpha_{j}^{m}+\alpha_{i j}+\tau \cdot t+\tau_{i}^{x} \cdot t+\tau_{j}^{m} \cdot t+\tau_{i j} \cdot t+\theta_{t}+\theta_{i t}^{x}+\theta_{j t}^{m}+\varepsilon_{i j t},
$$

where $\exp _{i j t}$ is the $\log$ of real export from country $i$ to $j$ at time $t$ and our main independent variable $G A B I_{i j t}$ with $K_{G A B I}$ variables based on the GABI index. I assume that all variables are uncorrelated with the error term. See Section 3.2.1 for a more extensive discussion on this. I assume that the error term $\varepsilon_{i j t}$ is not crosssectionally correlated and I allow it to be heteroscedastic and serially correlated.

The GABI index is part of the bilateral trade barrier and varies over three dimensions. However, the bilateral trade barrier consists also of many different country and country-pair specific characteristics, for example being landlocked and a common language, respectively. Therefore, I will add exporter and importer FE, $\alpha_{i}^{x} \alpha_{j}^{m}$ and country-pair FE $\alpha_{i j}$. Finally, I will also add an overall constant $\alpha$.

Exporter $\tau_{i}^{x} \cdot t$ and importer trend $\mathrm{FE} \tau_{j}^{m} \cdot t$ and country-pair trend FE $\tau_{i j} \cdot t$ are included, as proposed by Bun \& Klaassen (2007). They show that trends in the residuals, due to omitted variables, will lead to biased estimators, because the variables partly pick up the trending behavior in the residuals. Finally, we also add an overall trend $\tau \cdot t$ as is common in the time-series literature.

Time FE $\theta_{t}$ are included to capture for example the development of world income over time. Trade is affected by alternating periods of economic growth and economic crises, such as the oil (1973) and financial crisis (2008).

Finally, I will use the exporter-time $\theta_{i t}^{x}$ and importer-time $\theta_{j t}^{m} \mathrm{FE}$ to capture all variables that only vary over the exporter and time or the importer and time, e.g both MR terms and the RER ${ }^{10}$, but also unobserved exporter-time and importer-time heterogeneity. For my research question it does not matter that by adding country-time FE the impact of these variables is not identified, as my focus is on $G A B I_{i j t}$ and the former is not multicollinear with the latter. While Anderson \& van Wincoop (2003) show that ignoring the MR terms leads to substantial biases. Fally (2015) shows that the use of country FE in a cross-sectional analysis to capture the MR terms is consistent with the structural approach of Anderson \& van Wincoop (2003) and Egger \& Larch (2012) argue that the later actually leads to inconsistent estimates due to unobserved country specific effects. The additional time dimension in my analysis implies that country-time FE become the equivalent of country FE in a cross-section.

\footnotetext{
${ }^{10}$ Even though RER is an $i j t$ variable it is multicollinear with a linear combination of exporter-time and importer-time dummies because $R E R_{i j t}=R E R_{i U S t}-R E R_{j U S t}$; so $R E R_{i j t}$ can be written as a linear combination of $i t$ and $j t$ variables.
} 
To estimate (6), I will use LSDV. One other commonly used method to estimate gravity models is PPML, as proposed by Santos-Silva \& Tenreyro (2006). This approach has two main advantages. First, this approach is that it can deal with zero trade flows in the data. However, there are no zero trade flows for the countries in my sample; so this advantage plays no role of importance in this paper. Second, if one include exporter and importer FE in PPML, the sum of the estimated trade flows per exporting and per importing country equals the sum of the true value of the trade flows per exporting and importing country respectively, see Fally (2015) and Arvis \& Shepherd (2013), where LSDV will consistently overestimates the sum of the true values per exporting or per importing country due to Jensen's-inequality. This nice property is important in our general equilibrium analysis, see Section 5 . Therefore, I will also estimate the gravity model using PPML. In that case (6) the right-hand-side changes into an exponential model and the dependent variable is in levels.

Throughout the paper I will use Newey-West standard errors with 3 lags $^{11}$ (see Newey \& West $(1987,1994))$ to correct for heteroscedasticity and serial-correlation in $\varepsilon_{i j t}$. I use a $5 \%$ significance level throughout the paper.

\subsubsection{Endogeneity}

One potential source of endogeneity is due to omitted variables. The broad range of FEtypes included in to the model capture different sources of unobserved characteristics, such as country(-pair), country-(pair) trend, time and country-time characteristics preventing an omitted variable bias in the GABI estimates. Even non-linear characteristics can be partly captured by the wide range of FE-types.

Simultaneity is another potential source for endogeneity. There are two potential causes of simultaneity. First, exports have a positive effect on GDP so that GDP is endogenous. However, I look at bilateral exports and GDP and therefore, because the former is often small compared to the latter, the simultaneity effect is typically neglected. This is supported by Frankel (1997). This argument does not hold for intranational export flows. These are often between $70-60 \%$ of GDP. However, the share of intranational exports with respect to GDP is very constant over time or has a constant trend. Indeed, plots of these demeaned and detrended shares show that most fluctuation is within $2 \%$. So, the inclusion of country and country trend FE might substantially mitigates endogeneity in this case.

The second source of simultaneity is that high or relatively fast increasing exports between country-pairs can induce an FTA. BB2007 uses country-pair FE to capture the

\footnotetext{
${ }^{11}$ The number of lags is selected by calculating $4 *(T / 100)^{2 / 9}$ and rounding it down.
} 
level and Bun \& Klaassen (2007) additionally include country-pair trend FE to capture the trend, together resolving this simultaneity problem to a large extent.

Finally, measurement error is another source of endogeneity. In particular the GABI index is prone to measurement error. However, changing the EIA dummy variable into a GABI index will only decrease the measurement error, because it becomes more realistic. So, most likely the potential bias due to measurement errors in the economic integration variable will be reduced compared to using an EIA dummy.

To analyse whether endogeneity is not biasing the estimates, one can perform an IV regression. The literature offers many examples of such analysis. Bun \& Klaassen (2007) perform an IV regression using one period lagged FTA and Euro dummies as instruments and find that this did not lead to significantly different estimates. So, given that I use a similar model specification, I conclude that there is no indication that I need to worry about endogeneity in this paper.

\subsection{Data}

In this research I use 18 countries: all EU-15 countries excluding Belgium and Luxembourg $^{12}$, Canada (CN), Japan (JP), Norway (NW), the United States (US) and Switzerland (SW). I include intranational export flows, export from country $i$ to $i$, so I have 324 country-pairs. The data ranges from 1965-2011 $(T=47)$ resulting into 15228 observations. Economic integration for the EU already starts in 1957, especially in the first two Balassa stages, so I need to let the data start as early as possible. However, data availability in general and the poor quality of the bilateral export data in the early 60s forces us to choose our starting data not earlier than 1965.

For export flows from country $i$ to $j$ I use monthly nominal export data in US dollars from the IMF Direction Of Trade Statistics (DOTS) and convert it to exporter countries currency with the exchange rate from the International Financial Statistics (IFS) of the IMF. Next, I calculate yearly averages. To obtain real export I divide the obtained series by the exporter price index from AMECO of the European Commission. Finally, to ensure common scaling in real US dollars I divide by the purchasing power parity (PPP) of the US dollar in $i$ currency obtained from the OECD Economic Outlook, where we use the base year 2010 because all other indexes use the same base year.

To construct intranational export flows I follow the literature (cf. Bergstrand et al. (2015)) and take the total trade flows from country $i$ to the world from DOTS and

\footnotetext{
${ }^{12}$ Austria (OE), Denmark (DK), Finland (FN), France (FR), Germany (BD), Greece (GR), Ireland (IR), Italy (IT), the Netherlands (NL), Portugal (PT), Spain (ES), Sweden (SD), United Kingdom (UK).
} 
transform it from US dollars with the exchange rate from the IFS into $i$ currency. Next, I subtract this series from yearly nominal GDP obtained from AMECO, where I use the exchange rate from AMECO to denominate the latter in $i$ currency. To obtain real trade flows I use the same approach as before.

To be able to compare our GABI index with a binary FTA dummy, used standardly in the literature, we construct $F T A_{i j t}^{B B}$ based on BB2007. Table C.1 (Appendix C) displays all the different FTAs we take into account and all members' entry and exit dates.

We also created economic integration dummies based on our own GABI index. For each stage we construct a binary variant that equals one if the corresponding stage in the GABI index is non-zero, otherwise the binary variable is zero. These binary economic integration dummy variables are indicated with a $d$ in the superscript.

The remaining variables are the same as in Klaassen \& Teulings (2015b) and I refer to their data description for further information.

\section{Results}

In this section I will analyze the results of estimating the impact of the GABI index. First, I will focus on the first Balassa stage and explore the difference between the GABI and the dummy variable to estimate the effect of an FTA. Next, I will discuss the estimation results of all five Balassa stage. Throughout this section I will omit the ijt subscript for brevity.

\subsection{Free trade agreements}

Table 1: Estimated impact of FTA based on different FTA variable definitions

\begin{tabular}{lccccccc}
\hline \hline Lags of FTA & \multicolumn{3}{c}{ No } & & \multicolumn{3}{c}{ Yes } \\
\cline { 2 - 3 } \cline { 6 - 8 } No. of lags & - & - & - & & 11 & 11 & 7 \\
FTA variable & $F T A^{B B}$ & $F T A^{d}$ & $F T A$ & & $F T A^{B B}$ & $F T A^{d}$ & $F T A$ \\
\hline$F T A$ & $0.16^{*}$ & $0.09^{*}$ & $0.19^{*}$ & & $0.38^{*}$ & $0.45^{*}$ & $0.26^{*}$ \\
& $(0.02)$ & $(0.02)$ & $(0.03)$ & & $(0.04)$ & $(0.04)$ & $(0.04)$ \\
\hline \hline
\end{tabular}

$\overline{\text { The dependent variable is } e^{x p} p_{i j t} \text {. For the three models with lags of the FTA variable I only }}$ report the overall effect. Standard errors are between brackets. * indicates significance at $5 \%$ level.

To be able to compare GABI index with the use of binary dummy variables I estimate the impact of an FTA using three different specifications. The dummy variable $F T A^{B B}$ is based on an FTA dummy variable used by BB2007 (see Section 3.3), FTA 
is the first stage of the GABI index, so a gradual variable, and the dummy variable $F T A^{d}$ is 1 if FTA is non-zero. For a more extensive description of the latter two see also Section 2.3.

In Table 1 in the first three columns I display the estimation results for the static model. The estimation results for $F T A^{B B}$ and FTA are similar. However, the FTA estimate is considerably smaller than both estimates. This is remarkable, especially because $F T A^{d}$ and $F T A^{B B}$ are very similar being both dummy variables. The difference between these two variables is purely that $F T A^{B B}$ does not take into account two association agreements; Finland becomes associate EFTA member in 1961 and Greece signs an association agreement with the EU-6 in 1962. In the GABI index these two association agreements get both 2 points out of the possible 15 , but the $F T A^{d}$ variable cannot distinguish between a full and shallow FTA. So here it is better to omit shallow FTAs. However, when is an FTA shallow and when is it full? This a subjective and not so obvious choice that one has to make and the results show that it can influence the estimates quite heavily.

The estimated impact of FTA is 0.19 implying a $([\exp (0.19)-1] * 100=) 21 \%$ increase in exports. Similarly, the estimated impact of $F T A^{B B}$ is 0.16 .

This effect is considerably smaller than the estimated impact of 0.46 by BB2007 in a similar model (see BB2007 Table 5 p. 89). This can mostly be explained by my inclusion of $\tau_{i j} \cdot t$ (Section 6.2 confirms and further explain their importance). If I do not include $\tau_{i j} \cdot t$ I find an estimated impact of 0.51 for $F T A^{B B}$ (not shown).

Next, I will incorporate lags of the FTA variable to take dynamic FTA effects into account. The number of lags is based on significance. Possible dynamic effects are habit formation of consumers and exporters and importers that need time to adjust to the opening up of new markets due to a new FTA treaty. Besides the level effect I will add (lagged) first differences to capture the dynamic component, such that the former still captures the long-term effect and they are still comparable to the static estimates.

BB2007 also include lags in one of their model specification to model the time it takes to actually reduce tariffs after the introduction of an FTA, so called phase-in. However, the GABI index already captures this effect ensuring that including dynamics only captures the lagged response of consumers, exporters and importers on an FTA. So, the GABI index disentangles the phase-in dynamics from the actual dynamics on exports.

The last three columns in Table 1 display the result when including dynamics. For the GABI index variable I need to include seven lags indicating that it takes seven years before consumers, exporters and importer fully adjust to the new FTA. As a 
consequence the FTA effect increases to 0.26. For $F T A^{B B}$ I need to include 11 lags, substantially longer than for the FTA variable. BB2007 show that they need to include 10 year lags. ${ }^{13}$ Hence, due to the need to capture the phase-in one need to include more lags for $F T A^{B B}$. The same holds for $F T A^{d}$.

The estimated impact of both dummy FTA variables is substantially larger than that of FTA. Still, the estimated impact for $F T A^{B B}$ of 0.38 , a $44 \%$ increase in exports, is a lot smaller than the doubling found by BB2007 when including phase-in effects; they find an increase in exports of $114 \%$. This difference is again almost completely explained by the addition of $\tau_{i j} \cdot t$, omitting $\tau_{i j} \cdot t$ leads to an increase of $97 \%$ in exports (not shown).

Summarizing, I show that including shallow FTAs in a dummy variable influences the estimated impact. However, the researcher has to make a subjective decision when an FTA is shallow and should therefore be omitted. The GABI index allows us to distinguish between the depths of different FTAs and therefore circumventing this problem. Furthermore, I show that the gradual aspect of the GABI index allows me to no longer use FTA lags to capture the phase-in. Instead, the lags now solely capture the dynamic impact of an FTA.

\subsection{All stages in the GABI index}

In this section I will consider the estimated impact of the aggregate Balassa stages TEI and of the five incremental Balassa stages separately. In the first two columns of Table 2 I estimate the impact of TEI using a dummy variable based on the GABI index and the GABI index itself, respectively. In the third column I reestimate the latter model using PPML instead of LSDV. Finally, I repeat this comparison in column four to six using the five incremental Balassa stages separately. See Section 2.3 for a more extensive description of the variables.

In column two I estimate the impact of TEI to be 0.47 , implying a $60 \%$ increase in exports. This is between the median and mean of the meta-analysis by Cipollina \& Salvatici (2010).

With an estimated impact of 0.08, the estimated impact of TEI using a dummy variable, column one, is substantially smaller. The reason for this is that the dummy variable of TEI is very similar to the dummy variable of FTA because most countrypairs start the economic integration process with the first Balassa stage. So it is difficult to disentangle the first Balassa stage from TEI, when using dummies.

\footnotetext{
${ }^{13}$ They use data with a five year interval, so they only include two lags. However, this implies that the Phase-In period is 10 years.
} 
Table 2: Estimated impact of the GABI index using different model specifications

\begin{tabular}{|c|c|c|c|c|c|c|}
\hline \multirow[b]{2}{*}{ Description } & \multicolumn{3}{|c|}{ " Aggregate Balassa stages } & \multicolumn{3}{|c|}{ Incremental Balassa stages } \\
\hline & GABI Dum. & GABI & GABI, PPML & GABI Dum. & GABI & GABI, PPML \\
\hline TEI & 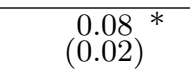 & ${ }_{(0.47}^{0.05)}{ }^{*}$ & 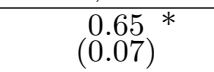 & & & \\
\hline FTA & & & & $\begin{array}{l}0.06 \\
(0.02)\end{array}{ }^{*}$ & $\begin{array}{l}0.14 \\
0.03)\end{array}{ }^{*}$ & $\begin{array}{l}0.24 \\
(0.06)\end{array}$ * \\
\hline$C U^{+}$ & & & & $\begin{array}{l}0.19 \\
(0.05)\end{array}$ * & $\begin{array}{l}0.17 \\
0.04)\end{array}$ * & 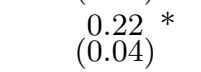 \\
\hline$C M^{+}$ & & & & $\begin{array}{c}-0.11 \\
(0.09)\end{array}$ & -0.27 (0.06) & -0.28 (0.05) \\
\hline$E U N^{+}$ & & & & $\begin{array}{c}0.01 \\
(0.03)\end{array}$ & $\begin{array}{c}0.03 \\
(0.08)\end{array}$ & $\begin{array}{l}0.18 \\
(0.06)\end{array} *$ \\
\hline$T E I^{+}$ & & & & $\begin{array}{l}0.15 \\
(0.10)\end{array}$ & $\begin{array}{l}0.29 \\
0.14)\end{array}$ * & 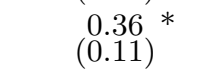 \\
\hline$\sum G A B I$ & - & - & - & 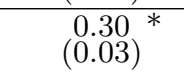 & 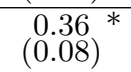 & 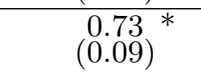 \\
\hline
\end{tabular}

The dependent variable is $e x p_{i j t}$. All models are estimated with LSDV unless described otherwise. The inclusion of dynamics is not displayed. Using LSDV, only FTA has 7 significant lags (see Table 1). The estimated FTA impact becomes $0.22(0.04)$ and the estimated $\sum G A B I$ becomes $0.45(0.09)$. All other estimates hardly change. Using PPML, both $F T A$ and $C U^{+}$have 5 significant lags. The estimated impact of FTA hardly changes and that of $C U^{+}$becomes 0.33 (0.05). The estimated $\sum G A B I$ becomes 0.85 (0.11). All other estimates hardly change. Standard errors are between brackets. * indicates significance at $5 \%$ level.

The estimated impact of TEI using PPML in column three is 0.65 and is substantially larger than its LSDV counterpart, still both estimates are in line with general findings.

By combining all EIAs into one variable I might miss important information one their individual contribution in increasing export. However, I cannot just add a dummy for every EIA because this leads to substantial amount of overlap in the dummies causing a collinearity problem. Therefore, I use the five incremental Balassa stages in GABI index as variables, because in these stages similar EIAs are weighted and combined leading to a reliable estimated impact for these five stages. In future research one can split up the different stages even further.

The estimated FTA impact in column five is 0.14 , that is a slight decrease compared to Table 1. The decrease is possibly explained by the fact that FTA and $C U^{+}$develop rather similar. Therefore, estimating a model with only FTA will cause it to partly capture the impact of $C U^{+} .14$

The estimated impact of $C U^{+}$is 0.17 . Hence, a $C U$, combining the first two Balassa stages, has a significant estimated impact of 0.31. This is in line with Roy (2010), who estimate that the impact of a $C U$ is bigger than that of an FTA.

The third stage, $C M^{+}$, is the only of the five stages that has a negative effect on

\footnotetext{
${ }^{14}$ If I omit $C U^{+}$, the estimated FTA impact increases to 0.17 , close to the estimate in Table 1 supporting this argumentation.
} 
exports. I find an estimated impact of -0.27 . This result may seem strange at first glance, that is, more integration reduces exports. However, it might actually sheds new light on the discussion of the relation between free factor movements, specifically that of capital, and exports. There is an ongoing debate about the tradeoff between export and foreign direct investment (FDI). If the cost of factor movement decreases it might be better for firms to engage in FDI to serve the local market instead of exporting, explaining a negative $\mathrm{CM}^{+}$effect. This is the so called proximity versus concentration trade-off. Among others Brainard (1997) finds empirical support for this tradeoff. Helpman et al. (2004) shows that the most productive firms engage into FDI and the second most productive firms engage in export. A CM makes FDI easier, lowering the threshold for less productive firms to engage in FDI and therefore reducing the average productivity of exporting firms. So, my results show that $\mathrm{CM}^{+}$favours proximity over concentration.

The estimated impact of $E U N^{+}$is not significant. The fact that standardization of relevant national laws and integration of economic policies does not have a big effect on exports when a CM market is already realized seems plausible. This estimate is also in line with Bun \& Klaassen (2007) who find that the Euro only lead to a small increase in exports, realizing that the introduction of the euro mainly leads to an increase of $E U N^{+}$. Another potential cause for the insignificant estimate is that $E U N^{+}$and $T E I^{+}$ are highly correlated leading to a collinearity problem. This is supported by the fact that omitting $T E I^{+}$leads to a significant estimated impact of $E U N^{+}$.

The estimated impact of $T E I^{+}$is 0.29 . This is the largest contribution to an increase in exports of all five stages implying that arranging policies at a supranational level leads to the most additional gains in exports.

If I sum all estimated impact of the five stages I find that the total significant impact on economic integration is 0.36 , this leads to a $43 \%$ increase in exports. This is very close to the median of $46 \%$ found by Cipollina \& Salvatici (2010) in their meta-analysis, but only half of their mean of $80 \%$.

In general the model in column four with dummy variables results into mainly insignificant estimates. A likely cause is the high degree of collinearity between the five dummy variables because these variables overlap and cannot disentangle countrypair specific differences in the depth and path of economic integration (for example see Figure 1a). Adding only five dummies is already causing problems and this exemplifies why I cannot add dummies for every EIA. Only the estimated impacts of the dummy variables for $F T A$ and $C U^{+}$are significant, because the dummy variables of different stages are very similar leading to no or weak identification of the estimated impact of 
the five stages. The FTA dummy variable estimate is still considerably smaller than its GABI index counterpart, while that of $C U^{+}$is similar to its GABI index counterpart. The sum of estimated impact of the five stages is 0.30 . That is similar to its GABI index counterpart. However, this ignores the fact that there are substantial deviations in the dummy variable estimates and that three stages are insignificant.

The estimated impact of the five stages in the GABI index when using PPML, column six, are in general more pronounced but in line with its LSDV counterparts and most estimate do not differ more than two times its corresponding standard error. There are three notable differences. First, the estimated impact of FTA and $C U^{+}$are both larger leading to a combined significant estimated $C U$ impact of 0.46 . Second, the estimated impact of $E U N^{+}$, being 0.18, is much larger and significant. Finally, the sum of the GABI index estimates is almost twice as large, being 0.73. However, this result is mainly driven by the first and fourth Balassa stages that are substantially larger than when we estimate the model with LSDV.

Summarizing, economic integration can lead to substantial increase in exports. The use of the GABI index allows us to identify both the impact of specific Balassa stages as well as TEI, where this is not possible when using dummy variables because are to collinear with each other. The PPML estimates are more pronounced but in line with the LSDV estimates.

\section{General equilibrium analysis}

In this section I will use the estimation results from Section 4 for a general equilibrium (GE) analysis on the effects of Brexit on exports, where I will investigate multiple scenarios. Furthermore, I investigate the potential gains in exports due to an FTA between the EU and the US, TTIP, and an FTA between the EU and Canada, CETA.

For the GE analysis I will use the approach proposed by Anderson et al. (2015). Their approach is based on the nominal gravity model. I will apply their method to both the nominal and real gravity model as defined in Section 3.1. The general idea of the approach can be summarized in five steps, for a more extensive description see Appendix A-B.

1. Estimate the gravity model, using PPML, by

$$
\operatorname{Exp}_{i j t}=b_{i j t}^{1-\sigma} \exp \left(\theta_{i t}^{x}+\theta_{j t}^{m}\right) \eta_{i j t}
$$


where the bilateral trade barrier is given by

$$
b_{i j t}^{1-\sigma}=\exp \left(G A B I_{i j t}^{\prime} \beta+\alpha_{i j}+\tau_{i j} \cdot t\right)
$$

and all other FE, see (6), are normalized to zero. Furthermore, the $\theta_{j t}^{m}$ of Switzerland and all $\alpha_{i j}$ and $\tau_{i j}$, where Switzerland is either the exporting or importing country, are normalized to zero. Output and expenditure are constructed based on the theoretical market clearance condition, $Y_{i}=\sum_{j} \operatorname{Exp}_{i j t}$ and $E_{j}=\sum_{i} \operatorname{Exp}_{i j t}$, respectively. Finally, use the estimate country-time FE and constructed output and expenditure to construct the supplier and consumer MR.

2. Construct a counterfactual $b_{i j t}^{c,(1-\sigma)}$, where the $c$ indicates that this is the counterfactual variable. I take the year 2007 for the counterfactual to change, since this year is most comparable with the current economic size and the level of export flows.

3. Re-estimate $\theta_{i t}^{x}$ and $\theta_{j t}^{m}$ using (7), while keeping $b_{i j t}^{c,(1-\sigma)}$ fixed, to analyze the consequences of the counterfactual on bilateral export flows conditional on output and expenditure calculated in step 1; so only the MR will change in this step.

4. Next, allow output and expenditure to change as well, resulting into a full endowment GE as follows. First, use the results from step 3 to construct equilibrium prices with the estimated country-time FE and combine them with the MR to construct a new bilateral export variable. Use the latter to re-estimate $\theta_{i t}^{x}$ and $\theta_{j t}^{m}$ using (7) keeping $b_{i j t}^{c,(1-\sigma)}$ fixed. Subsequently, update output and expenditure based on the estimated bilateral exports using the market clearance condition. Next, use these two and the newly estimated country-time FE to re-construct both MR. Finally, update the equilibrium prices with the newly estimated country-time FE. Iterate by repeating step 4 until the equilibrium prices converge.

5. Finally, calculate the percentage change of the variables of interest in the full endowment GE case calculated in step 4 with respect to the baseline case calculated in step 1.

This GE analysis only works well when we use PPML to estimate the empirical gravity model. This is because in step 4 the GE analysis uses the estimated bilateral exports and the theoretical market clearance condition to update output and expenditure. Fally (2015) and Arvis \& Shepherd (2013) show that, if we include at least exporter and importer FE, the exporter and importer specific sum of the estimated export flows are equal to the exporter and importer specific sum of the actual export flows respectively, 
due to the resulting moment conditions. However, if I uses LSDV instead of PPML, I will consistently overestimate output and expenditure due to the Jensen's inequality.

Note that this GE analysis assumes that the country-time FE only capture the MR terms. However, it is possible that they capture other source of unobserved heterogeneity, for example measurement error. Klaassen \& Teulings (2015a) already show that this might be the case. So, it might be that the theoretical gravity model does not hold empirically (see also Head \& Mayer (2014) for a more extensive discussion). However, this is beyond the scoop of this paper.

To be able to calculate the equilibrium prices I need to set $\sigma$, the elasticity of substitution. Anderson \& van Wincoop (2004) review different studies investigating the size of the elasticity of substitution. They conclude that most findings are in the range of five and ten. Therefore, I choose $\sigma=7$, something in between.

Finally, I report bootstrapped $95 \%$ confidence bands throughout this section. To construct these bands I use the residual bootstrap method with 200 draws. I keep $i$ fixed for each country-pair and randomly draw from all importers $j$ to allow for exporter heterogeneity. Furthermore, I divide the complete time period in blocks with size 10 and draw only from these blocks for this specific period to allow for time heterogeneity. It is possible with residual bootstrap that the export flow becomes negative, in that case I take the absolute value of the residuals and reconstruct the export flows.

If I use the real gravity model by Klaassen \& Teulings (2015a), step 4 in the algorithm is no longer needed, because real output does not change (as is also assumed in the Nominal model) and changes in real expenditure are captured by the importer-time FE, which is already updated in step 3 .

\section{$5.1 \quad$ Brexit}

The countdown for Brexit started in March 2017 when the UK initiated article 50. In two years the UK and the EU have to negotiate an agreement, because otherwise after March 2019 the UK will automatically leave the EU ending all EIAs. The outcome of Brexit is uncertain, but there are several scenarios. The least disruptive is the soft Brexit, where the UK is still part of the SEA and the CU but no longer takes part in supranational bodies overlooking economic policy cooperation. In the hard Brexit the UK leaves the SEA and the CU and only has an FTA with the EU. Finally, the worst case scenario is when the negotiations fail, for example when there is no agreement after two years, and the UK ends all EIAs with the EU, I call this very hard Brexit. I can estimate these different Brexit scenarios using the estimated impacts of the GABI index for the different Balassa stages from Section 4.2. 
In Figure 3 I display the depth of economic integration in the five Balassa stages at the start of Brexit between the UK and five other European countries based on the GABI index. The country-pair UK-Germany is representative for all EU countries except Denmark and Sweden, which are represented separately. The UK has no EIAs with Canada, Japan and the US. This figure shows what is at stake for the UK and the EU during the Brexit negotiations.

Figure 3: Depth of the economic integration stages at the start of Brexit for UK- $j$.

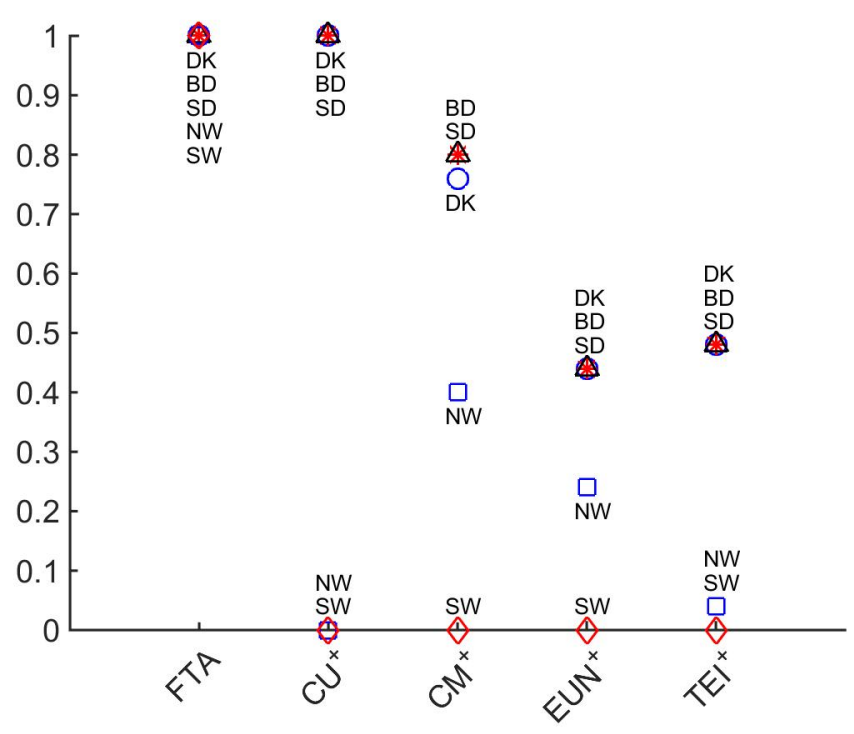

In Table 3 I display the result of four different Brexit scenarios ranging from soft to very hard Brexit. In each scenario the UK leaves on additional stage. For each scenario I will look at the country specific percentage change of nominal and real export, excluding intranational export flows, and of real GDP, where the latter is derived using (A.20). Finally, I also report the percentage change of nominal and real export for exports of the UK to the EU and vice versa. 


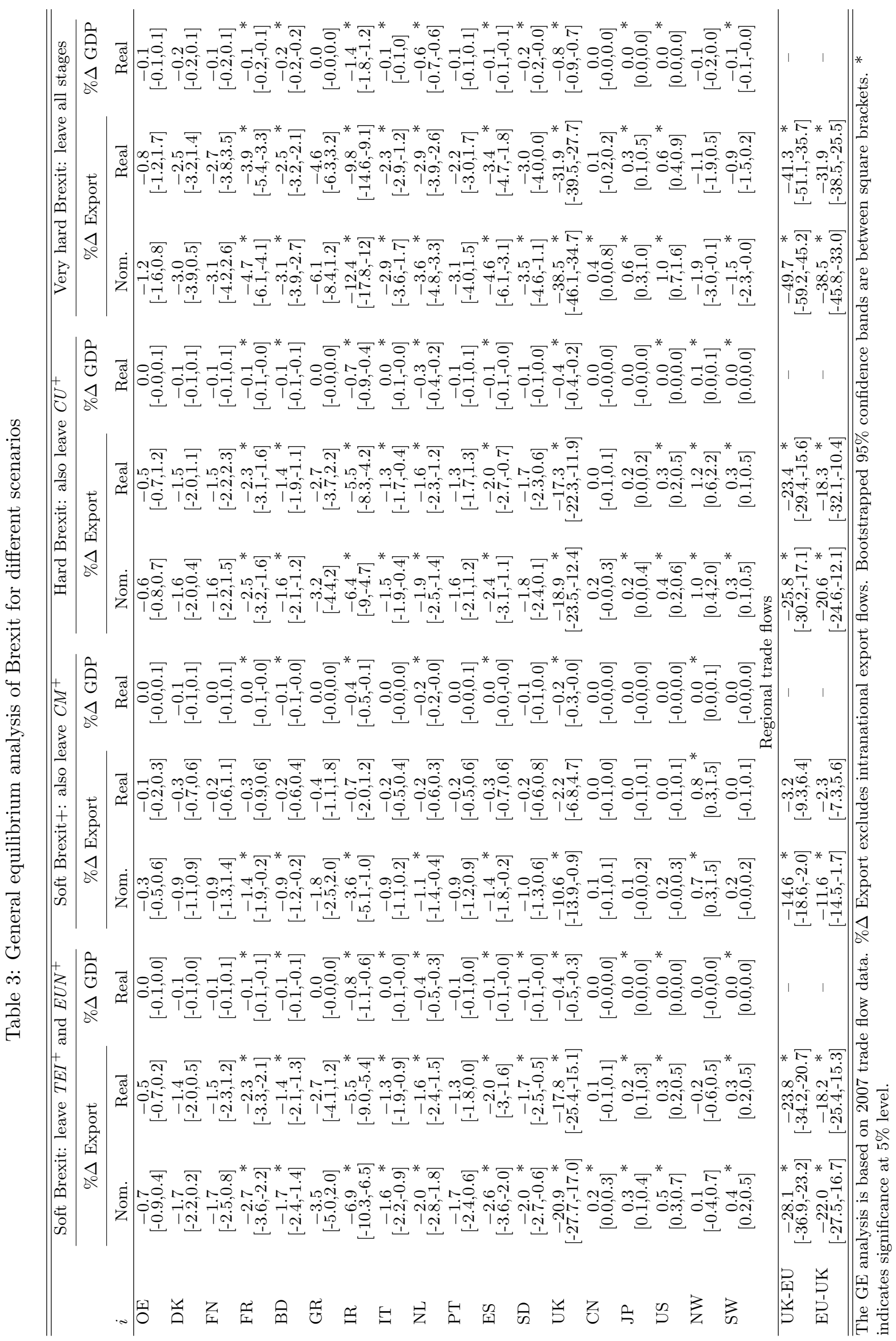


In the first scenario, soft Brexit, the UK leaves Balassa stages 5 and $4, \mathrm{TEI}^{+}$ and $E U N^{+}$, respectively. These two stages encompass supranational bodies to arrange cooperation on fiscal and monetary policy and standardization of national laws to improve economic policy cooperation, respectively. It is most likely that this is going to be the minimal outcome of Brexit. Both the EU countries and the UK lose in terms of real exports, but not all loses are significant. The economic mechanism behind this is that an increase in the bilateral trade barrier $b_{i j t}$ leads to higher costs for the UK to import from the EU reducing export and vice versa (see also Section 3.1). The significant loses are somewhere between $2.3 \%$ and $1.4 \%$ except for Ireland that loses more than double compared to the worst of all other EU countries. This can be explained by the close Anglo-saxon ties between Ireland and the UK. However, no EU country loses so much as the UK itself with $17.8 \%$. But it is Ireland that suffers the most in terms of real GDP, double that of the UK itself. The Netherlands is another country that is hit particularly hard with its small open economy. The UK loses more than the EU in terms of the total export between the UK and the EU. The fall in export from the UK to the EU is actually more than the overall fall implying that the UK partially compensates the loss by exporting more to other non-EU countries, i.e. trade diversion, mitigating the cost of Brexit. Because the exporter MR of the UK rises, due to a higher bilateral trade barrier with the EU, there is less demand for its goods leading to a drop in the price, so the UK becomes cheaper for non-EU countries leading to more exports to non-EU countries. All non-EU countries gain, from the Brexit, although the gains are small and not always significant. This is a typical example of trade diversion (see Section 2.1).

The second scenario is a soft Brexit+, where the UK additionally leaves Balassa stage $3, \mathrm{CM}^{+}$; so leaving the SEA and restricting free movement of labour. Oddly enough this scenario leads to lower real exports lose than the first scenario. This is because $C M^{+}$has a negative coefficient (see Table 2) due to the proximity versus concentration trade-off. This does not necessarily imply that the second scenario is better than the first scenario. One also has to analyze the effects of a decrease in labor and capital mobility on real GDP through other channels like FDI and productivity. None of the real export loses are significant, accept for Norway which gains due to trade diversion. UK loses the most in terms of nominal exports, again followed by Ireland. The UK is able to mitigate parts of the Brexit cost by trade creation with non-EU countries. Ireland loses the most and twice as much as the UK in terms of real GDP.

The third scenario is a hard Brexit, where the UK leaves also Balassa stage $2, C U^{+}$. In terms of size the effects are relatively comparable to a soft Brexit. The UK loses by 
far the most from Brexit. The EU loses less from Brexit, but especially Ireland is hit hard. The US, Norway and Switzerland gain from Brexit through trade diversion.

Finally, the fourth scenario, the very hard Brexit, explores the consequences when the negotiations completely fail and the UK stops all economic cooperation with the EU leaving all five Balassa stages. This is by far the most harmful scenario for both the UK and the EU. The UK's real export is reduced by $31.9 \%$ leading to a $0.8 \%$ decrease in real GDP, but similar to the other three scenarios the UK mitigates the cost of Brexit partly by trade diversion to other non-EU countries. Also Ireland loses substantially with $9.8 \%$ leading to a $1.4 \%$ decrease in real GDP. Ireland again loses by far the most in terms of real GDP. Overall the pattern is similar to the other three scenarios. Note that Switzerland and Norway, where it is only significant for the former, actually lose from the very hard Brexit because the loss in exports due to the loss of an FTA (see Figure 3) with the UK outweighs the export gains from trade diversion. All other non-EU countries gain from a very hard Brexit thanks to trade diversion. This last scenario shows the importance for the UK and the EU to agree upon a transition agreement for the years between March 2019 and the day that they reach a final agreement. Because hammering out a Brexit agreement takes likely more than two years after which automatically all treaties between the EU and the UK are cancelled, as is specified by article 50 .

As a final note I want to stress that these numbers, as presented above, should not be considered as the final number for the cost of different Brexit scenarios. As I mentioned before in this simple GE analysis I only look at the effects on exports and completely ignore the effects on the financial sector, FDI, productivity et cetera. These will most likely increase the impact of Brexit.

\section{$5.2 \quad$ TTIP and CETA}

In Table 4 I display the results of an FTA between the US and the EU (TTIP) and between Canada and the EU (CETA). I assume that both FTAs are complete, i.e. FTA gets full points. The setup of the table is similar as that of Table 3 .

The US gains from TTIP are substantial with a $11.1 \%$ increase in real exports and $0.1 \%$ increase in real GDP. The gains in real exports for the US with only the EU are even bigger, but the overall effect is smaller due to trade diversion. The UK and Ireland gain the most from all the EU countries, most likely due to their close Anglo-saxon ties with the US, where Ireland has the biggest increase in real GDP. All significant gains of the EU countries are between $1.6 \%-2.1 \%$ increase in exports and $0.4 \%-0.1 \%$ increase in real GDP. Non-EU countries experience a decrease in real exports due to 
Table 4: General equilibrium analysis of TTIP and CETA

\begin{tabular}{|c|c|c|c|c|c|c|}
\hline \multirow[b]{3}{*}{$i$} & \multicolumn{3}{|c|}{ TTIP } & \multicolumn{3}{|c|}{ CETA } \\
\hline & \multicolumn{2}{|c|}{$\% \Delta$ Export } & \multirow{2}{*}{$\begin{array}{c}\% \Delta \text { GDP } \\
\text { Real }\end{array}$} & \multicolumn{2}{|c|}{$\% \Delta$ Export } & \multirow{2}{*}{$\begin{array}{c}\% \Delta \text { GDP } \\
\text { Real }\end{array}$} \\
\hline & Nom. & Real & & Nom. & Real & \\
\hline $\mathrm{OE}$ & $\begin{array}{c}1.3 \\
{[-2.4,2.1]}\end{array}$ & $\begin{array}{c}0.9 \\
{[-2.4,1.4]}\end{array}$ & $\begin{array}{c}0.1 \\
{[-0.2,0.1]}\end{array}$ & $\begin{array}{c}0.2 \\
{[-3.0,0.4]}\end{array}$ & $\begin{array}{c}0.1 \\
{[-2.8,0.3]}\end{array}$ & $\begin{array}{c}0.0 \\
{[-0.2,0.0]}\end{array}$ \\
\hline DK & {$\left[\begin{array}{c}1.4 \\
{[-4.7,2.1]}\end{array}\right.$} & {$[-5.3,1.6]$} & {$\left[\begin{array}{c}0.1 \\
{[-0.3,0.1]}\end{array}\right.$} & {$\left[\begin{array}{c}0.2 \\
{[-4.2,0.5]}\end{array}\right.$} & {$\left[\begin{array}{c}0.2 \\
{[-4.3,0.4]}\end{array}\right.$} & {$\left[\begin{array}{c}0.0 \\
{[-0.3,0.0]}\end{array}\right.$} \\
\hline FN & $\begin{array}{c}2.6 \\
{[-2.6,3.9]}\end{array}$ & $\begin{array}{c}2.0 \\
{[-3.4,3.0]}\end{array}$ & $\begin{array}{c}0.1 \\
{[-0.2,0.2]}\end{array}$ & $\begin{array}{c}0.4 \\
{[-4.3,0.7]}\end{array}$ & $\begin{array}{c}0.3 \\
{[-4.5,0.5]}\end{array}$ & $\begin{array}{c}0.0 \\
{[-0.3,0.0]}\end{array}$ \\
\hline FR & $[2.4,4.2]]^{*}$ & {$[1.4,3.0]^{*}$} & $[0.1,0.1]]^{*}$ & $\begin{array}{c}0.3 \\
{[-0.7,0.5]}\end{array}$ & {$\left[\begin{array}{c}0.2 \\
{[-0.7,0.4]}\end{array}\right.$} & $\begin{array}{c}0.0 \\
{[-0.0,0.0]}\end{array}$ \\
\hline $\mathrm{BD}$ & {$[2.3,3.7]^{*}$} & {$[1.2,2.6]^{*}$} & {$[0.1,0.2]^{*}$} & $\begin{array}{c}0.2 \\
{[-0.3,0.4]}\end{array}$ & $\begin{array}{c}0.1 \\
{[-0.4,0.2]}\end{array}$ & $\begin{array}{c}0.0 \\
{[-0.0,0.0]}\end{array}$ \\
\hline GR & $\begin{array}{c}3.9 \\
{[-8.5,5.7]}\end{array}$ & $\begin{array}{c}2.5 \\
{[-8.6,3.6]}\end{array}$ & $\begin{array}{c}0.0 \\
{[-0.1,0.0]}\end{array}$ & {$\left[\begin{array}{c}0.4 \\
{[-6.8,0.7]}\end{array}\right.$} & {$\left[\begin{array}{c}0.3 \\
{[-7.3,0.6]}\end{array}\right.$} & $\begin{array}{c}0.0 \\
{[-0.1,0.0]}\end{array}$ \\
\hline IR & {$[2.5,3.0]^{*}$} & {$[1.5,5.6]^{*}$} & {$[0.0,0.8]$} & {$\left[\begin{array}{c}0.2 \\
{[-3.1,0.3]}\end{array}\right.$} & {$\left[\begin{array}{c}0.1 \\
{[-2.5,0.2]}\end{array}\right.$} & $\begin{array}{c}0.0 \\
{[-0.4,0.0]}\end{array}$ \\
\hline IT & $[0.6,3.5]]^{*}$ & {$\left[\begin{array}{c}1.7 \\
{[-0.1,2.4]}\end{array}\right.$} & {$[0.0,0.1]^{0.1}$} & {$\left[\begin{array}{c}0.3 \\
{[-1.0,0.5]}\end{array}\right.$} & {$\left[\begin{array}{c}0.2 \\
{[-0.9,0.3]}\end{array}\right.$} & {$\left[\begin{array}{c}0.0 \\
{[-0.0,0.0]}\end{array}\right.$} \\
\hline NL & {$[1.8,3.3]^{*}$} & {$[0.8,2.6]^{*}$} & {$[0.3,0.6]^{0.4}$} & {$\left[\begin{array}{c}0.2 \\
{[-0.8,0.4]}\end{array}\right.$} & {$\left[\begin{array}{c}0.1 \\
{[-0.8,0.3]}\end{array}\right.$} & {$[-0.2,0.1]$} \\
\hline $\mathrm{PT}$ & {$[-5.3,2.0]$} & {$[-4.6,1.2]$} & {$\left[\begin{array}{c}0.0 \\
{[-0.3,0.1]}\end{array}\right.$} & {$\left[\begin{array}{c}0.2 \\
{[-4.3,0.5]}\end{array}\right.$} & $\begin{array}{c}0.1 \\
{[-3.4,0.3]}\end{array}$ & {$[-0.2,0.0]$} \\
\hline $\mathrm{ES}$ & {$\left[\begin{array}{c}1.8 \\
{[-1.2,2.8]}\end{array}\right.$} & $\begin{array}{c}1.1 \\
{[-1.0,1.7]}\end{array}$ & {$\left[\begin{array}{c}0.0 \\
{[-0.0,0.1]}\end{array}\right.$} & $\begin{array}{c}0.2 \\
{[-2.0,0.5]}\end{array}$ & {$\left[\begin{array}{c}0.1 \\
{[-1.8,0.3]}\end{array}\right.$} & {$\left[\begin{array}{c}0.0 \\
{[-0.1,0.0]}\end{array}\right.$} \\
\hline $\mathrm{SD}$ & $\begin{array}{c}2.3 \\
{[-1.7,3.3]}\end{array}$ & {$\left[\begin{array}{c}1.8 \\
{[-1.5,2.5]}\end{array}\right.$} & $\begin{array}{c}0.1 \\
{[-0.1,0.2]}\end{array}$ & $\begin{array}{c}0.3 \\
{[-2.5,0.6]}\end{array}$ & {$\left[\begin{array}{c}0.2 \\
{[-2.5,0.4]}\end{array}\right.$} & {$\left[\begin{array}{c}0.0 \\
{[-0.2,0.0]}\end{array}\right.$} \\
\hline UK & {$[6.0,9.1]^{*}$} & {$[3.7,6.8]^{*}$} & {$[0.1,0.2]$} & {$[-0.1,1.5]$} & $\begin{array}{c}0.6 \\
{[-0.6,0.9]}\end{array}$ & {$\left[\begin{array}{c}0.0 \\
{[-0.0,0.0]}\end{array}\right.$} \\
\hline $\mathrm{CN}$ & {$\left[\begin{array}{c}-0.9 \\
{[-1.7,-0.9]}\end{array}\right.$} & {$[-0.4,-0.1]$} & {$\left[\begin{array}{cc}0.0 & * \\
{[-0.0,-0.0]}\end{array}\right.$} & $\begin{array}{c}2.5 \\
{[-0.8,3.1]}\end{array}$ & $\begin{array}{c}1.6 \\
{[-1.4,1.9]}\end{array}$ & {$\left[\begin{array}{c}0.2 \\
{[-0.1,0.2]}\end{array}\right.$} \\
\hline JP & {$\left[\begin{array}{c}-0.7 \\
{[-1.3,-0.6]}\end{array}\right.$} & {$[-0.4,-0.1]$} & {$\left[\begin{array}{c}0.0 \\
{[-0.0,-0.0}\end{array}\right.$} & {$[-0.3,0.1]$} & {$[-0.1,0.1]$} & {$[-0.0,0.0]$} \\
\hline US & $\begin{array}{c}17.9 \\
{[17.3,24.8]}\end{array}$ & $\begin{array}{c}11.1 \\
{[8.9,15.3]}\end{array}$ & {$[0.1,0.2]{ }^{*}$} & {$[-0.6,0.1]$} & {$[-0.2,0.2]$} & {$\left[\begin{array}{c}0.0 \\
{[-0.0,0.0]}\end{array}\right.$} \\
\hline NW & {$\left[\begin{array}{c}-0.4 \\
{[-0.8,-0.2]}\end{array}\right.$} & {$[-0.6,-0.1]$} & {$\left[\begin{array}{rr}0.0 & * \\
{[-0.1,-0.0]}\end{array}\right.$} & {$[-0.2,0.3]$} & {$[-0.2,0.4]$} & {$[-0.0,0.0]$} \\
\hline SW & {$\left[\begin{array}{cc}-0.5 & * \\
-0.9,-0.4\end{array}\right]$} & {$\left[\begin{array}{c}-0.3 * \\
{[-0.5,-0.1]}\end{array}\right.$} & {$\left[\begin{array}{c}0.0 \\
{[-0.0,-0.0]}\end{array}\right.$} & {$\left[\begin{array}{c}0.0 \\
{[-0.1,0.2]}\end{array}\right.$} & {$[-0.1,0.2]$} & {$[-0.0,0.0]$} \\
\hline \multicolumn{7}{|c|}{ Regional trade flows for $k=\mathrm{US}$ and $k=\mathrm{CN}$} \\
\hline$k$-EU & $\begin{array}{rr}46.4 & * \\
{[48.8,67.7]}\end{array}$ & $\begin{array}{cc}28.6 & * \\
{[25.8,42.0]}\end{array}$ & - & $\begin{array}{cc}41.3 & * \\
{[42.4,63.6]}\end{array}$ & $\begin{array}{c}27.2{ }^{*} \\
{[25.6,42.0]}\end{array}$ & - \\
\hline $\mathrm{EU}-k$ & $\begin{array}{r}32.6{ }^{*} \\
{[26.9,44.8]}\end{array}$ & $\begin{array}{r}23.5 \\
{[15.7,31.2]}\end{array}$ & - & $\begin{array}{r}39.4{ }^{*} \\
{[34.1,54.1]}\end{array}$ & $\begin{array}{c}25.8{ }^{*} \\
{[19.0,34.7]}\end{array}$ & - \\
\hline
\end{tabular}

The GE analysis is based on 2007 trade flow data. \% $\Delta$ Export excludes intranational export flows. Bootstrapped $95 \%$ confidence bands are between square brackets. indicates significance at $5 \%$ level. 
trade diversion. Surprisingly it is Norway and Switzerland that are hit hardest. One would expect that Canada would suffer the most, being very close to the US, but it actually suffers the least from all four non-EU countries.

The gains of CETA for Canada are small compared to the gains of TTIP for the US and moreover they are insignificant. The same holds for all the EU countries and non-EU countries. Still, the UK, of all EU countries, gains the most from CETA. Unlike with TTIP, Ireland does not gain that much from CETA, it has actually one of the smallest gains. The trade diversion effects for the non-EU countries are small. The US is hit the hardest, most likely because it exports similar products as the EU to Canada. This is supported by the two-digit Standard International Trade Classifications (SITC), revision 3, of the UN Commodity Trade Statistics Database (UN Comtrade), which shows that out of the ten most exported categories by the US to Canada and the EU to Canada seven overlap. Hence, lower trade barriers between Canada and the EU leads probably to trade diversion away from the US towards the EU. It is not clear why CETA leads such smaller gains than TTIP. Further research must shed more light on this result.

\section{Robustness analysis}

In this section I will perform two robustness checks. First, I relax the homogeneous parameter assumption and allow for exporter and importer specific parameters. Second, I investigate the effect of omitting $\tau_{i j} \cdot t$ on the GABI index estimates.

\subsection{Parameter heterogeneity}

In column 1 and 2 of Table 5 I investigate relaxing the homogeneous parameter assumption. I allow for an overall parameter and both exporter- and importer-specific parameters for the GABI index variables, for example

$$
G A B I_{i j t}^{\prime} \beta+\sum_{i} G A B I_{i j t}^{\prime} \beta_{i}^{x}+\sum_{j} G A B I_{i j t}^{\prime} \beta_{j}^{m}
$$

where I normalize the mean of both the exporter- and importer-specific parameters to zero to prevent multicollinearity with the overall GABI variable. So, I untangle the effects of the former two from the overall effect and the overall plus the exporter- or importer-specific effect is the total exporter- or importer-specific effect, respectively. For brevity I only report the overall effect in Table 5, but in Table C.2 I also report all heterogeneous parameters. I do not consider country-pair specific parameters because 
Table 5: Sensitivity results relaxing different model assumptions in (6)

\begin{tabular}{|c|c|c|c|c|}
\hline Description & Hetero & Par. & \multicolumn{2}{|c|}{ no $\tau_{i j}$} \\
\hline TEI & $\begin{array}{l}0.40 \\
(0.13)\end{array}{ }^{*}$ & & $\begin{array}{l}0.86 \\
(0.06)\end{array}{ }^{*}$ & \\
\hline FTA & & 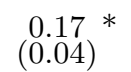 & & $\begin{array}{l}0.36 \\
(0.04)\end{array}$ * \\
\hline$C U^{+}$ & & $\begin{array}{l}0.08 \\
(0.06)\end{array}$ & & $\begin{array}{l}0.08 \\
(0.05)\end{array}$ \\
\hline$C M^{+}$ & & $\begin{array}{c}-0.16 \\
(0.17)\end{array}$ & & $\begin{array}{c}-0.11 \\
(0.07)\end{array}$ \\
\hline$E U N^{+}$ & & $\begin{array}{c}-0.11 \\
(0.16)\end{array}$ & & $\begin{array}{l}0.30 \\
(0.10)\end{array}$ * \\
\hline$T E I^{+}$ & & $\begin{array}{l}0.52 \\
(0.17)\end{array} *$ & & $\begin{array}{c}0.24 \\
(0.18)\end{array}$ \\
\hline$\sum G A B I$ & - & $\begin{array}{c}0.50 \\
(0.19)\end{array}{ }^{*}$ & - & $\begin{array}{l}0.87 \\
(0.09)\end{array}{ }^{*}$ \\
\hline
\end{tabular}

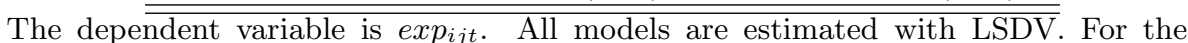
heterogeneous parameter estimates I only report the overall results. For the country specific results see Table C.2. Standard errors are between brackets. * indicates significance at $5 \%$ level.

there is not enough identifying power due to limited amount of time periods.

In column 1 of Table 5 I allow for heterogeneity in the estimated impact of TEI. To test whether the heterogeneous parameters are significantly different from zero, I performed a Wald-test testing the null-hypothesis $H_{0}: \beta_{i}^{x}=\beta_{j}^{m}=0$. For column 1 I clearly reject the null hypothesis finding a Wald-statistic of 89 and a corresponding p-value, based on the usual $\chi^{2}$-distribution with $29 \mathrm{DoF}$, of $5.4 \times 10^{-8}$. The overall impact is slightly smaller than in Table 2. The exporting countries Denmark, France, the Netherlands and the UK all have a significant additional estimated positive gain. So in general, open economies gain more from economic integration than other countries. Although Germany did not have a significant additional gain. There were no exporting countries that suffer from economic integration. Portugal and Norway have significant additional gains as importing countries from economic integration. The importing countries Finland and Ireland actually have a net loss from economic integration.

In column 2 I display the estimated impacts of the five incremental Balassa stages. I clearly reject the null hypothesis $H_{0}: \beta_{i}^{x}=\beta_{j}^{m}=0$ finding a Wald-statistic of 416 and a corresponding p-value, based on the usual $\chi^{2}$-distribution with 127 degrees of freedom $(\mathrm{DoF})$, smaller than $1.0 \times 10^{-16}$. In Table C.2 I also report the Wald-test results for testing $H_{0}: \beta_{i}^{x}$ and $H_{0}: \beta_{j}^{m}=0$ per stage separately. Only for the $\beta_{j}^{m}$ of $C U^{+}$and the $\beta_{i}^{x}$ of $C M^{+}$can I not reject the null-hypothesis.

The overall impact of FTA is similar to its homogeneous counterpart in Table 2. However, some countries experience some substantial significant deviations from the overall effect if they are exporting. The overall effect is almost completely offset in Germany and the Netherlands and in Denmark the negative effect is even bigger. On 
the other hand Greece, Ireland and Portugal, in a smaller degree, have substantially additional benefits as exporters from an FTA compared to the overall effect. So it appears that as exporters open economies do not gain as much from an FTA as relatively closed economies. On the importer side Italy gains less from an FTA, while Spain and Norway gain substantially more in addition to the overall effect.

The overall impact of $C U^{+}$is more than halved compared to the homogeneous impact in Table 2 and even becomes insignificant. However, countries like Germany, the Netherlands and the UK gain substantially more from a $\mathrm{CU}^{+}$as exporting country. The countries Denmark, Greece and Sweden lose from a $C U^{+}$. So open exporting economies that lose from an FTA gain with a $C U^{+}$, except for Denmark that loses in both stages. Italy is the only importing country that has additional gains from a $C U^{+}$. There are no importing countries that lose from a $C U^{+}$.

The overall impact of $\mathrm{CM}^{+}$is almost halved compared to Table 2 and becomes insignificant, although it is still negative. The Netherlands and Portugal have as exporting countries an additional significant negative impact. That the Netherlands loses so much from a $\mathrm{CM}^{+}$can be explained with proximity versus concentration trade off and the fact that it has one of the biggest net inflows of FDI in percentage of GDP. There is no exporting country that has an additional significant positive contribution. As importer, Greece has an additional significant negative estimated impact and the UK a positive estimated impact.

The overall impact of $E U N^{+}$is insignificant like in Table 2. However, Finland, Spain and the UK gain as exporter substantially from an $E U N^{+}$. Italy and Spain have additional gains importers from the $E U N^{+}$. There is no significant negative exporteror importer-specific effect. So one can tentatively conclude that, if $E U N^{+}$has any significant overall effect, it is a positive effect.

Finally, the overall effect of the fifth Balassa stage $T E I^{+}$is substantially larger than in Table 2. For the exporting countries Denmark, Greece and Sweden have significant substantial additional gains. On the other hand Ireland, Spain and the UK lose substantially. For the importing countries only Italy and Spain lose. Overall the estimated exporter- and importer-specific effects of $\mathrm{TEI}^{+}$are the most dispersed of all Balassa stages.

Summing all five overall Balassa stages, I find a larger estimate than what I find in Table 2, but its standard error is also much bigger making this difference hard to asses.

Overall relaxing the homogeneous parameter assumption leads to more or less comparable results with the results in Table 2. Still, I reject the null-hypothesis that the heterogeneous parameters are not significantly different from zero. The reduced 
power, due to the heterogeneous parameters, might explain why I find more insignificant estimates. The most important insight from heterogeneous parameters is that open economies in general seem to benefit more from economic integration than closed economies, except for the FTA stage where it is the other way around. Further research in this area is needed to confirm this observation.

\subsection{No country-pair trend FE}

Although the inclusion of country-pair trend $\mathrm{FE} \tau_{i j} \cdot t$ is already becoming more common after the paper of Bun \& Klaassen (2007) (cf. Baier et al. (2014) and Bergstrand et al. (2015)), it is still not a standard future in empirical gravity models.

In Table 5 I show in column 3-4 what happens with the estimated impact of different Balassa stages, if I do not include $\tau_{i j} \cdot t$. I find a more than doubling in the FTA effect compared to Table 2 estimates, while the estimated $C U^{+}$and $C M^{+}$effect both halve and even become insignificant. At the same time the estimated $E U N^{+}$effect increases tenfold and becomes significant. This supports Bun \& Klaassen (2007), who find that the effect of the euro on exports becomes highly significant if one does not add countrypair trend FE. Finally, the estimated $T E I^{+}$effect stays almost the same but the effect becomes insignificant. The sum of the estimated effects increases substantially and is almost identical to the estimated aggregate TEI effect in column three, the latter is almost double that of the estimate in Table 2.

If I perform a Wald-test to test $H_{0}: \tau_{i j}=0$, I clearly reject the null-hypothesis finding a Wald-statistic of 7661 and a corresponding p-value, based on the usual $\chi^{2}$ distribution with $289 \mathrm{DoF}$, smaller than $1.0 \times 10^{-16}$. Hence, omitting $\tau_{i j} \cdot t$ leads to substantially biased estimates.

\section{Conclusion}

In this paper I have constructed a new way to measure the bilateral and gradual aspects of economic integration, the gradual and bilateral integration (GABI) index. It uses the principle of the multilateral ECB index that divides EIAs into smaller events, assigning each with a weighting to one of the five Balassa stages of economic integration, the higher the weighting the bigger the contribution to economic integration. The GABI is constructed for the five Balassa stages as well as for the aggregate of economic integration.

This new measure has four advantages. First, it allows for differences in both the depth and path of economic integration for all five Balassa stages in contrast with the 
binary dummy variable, which is commonly used in the literature to capture economic integration. Second, it allows for the identification of the different Balassa stages of economic integration, which is often not possible with dummy variables because they overlap causing potential multicollinearity. Third, it allows for identification of the dynamic impact of the Balassa stages because lags solely capture the dynamics instead of partly capturing the gradual aspect of economic, as is the case with dummy variables. Finally, opposite to the multilateral ECB index, its bilateral aspects allow me to use it as dependent variable in a bilateral export model.

I use a gravity model framework to estimate the impact of the GABI index for the five Balassa stages using different model specifications and estimation methods. We find that accounting for the depth and path of economic integration improves the estimation results and therefore the GABI index indeed allows for a better identification of both the long-run and the dynamic impact of the five Balassa stages.

Next, I use the estimated impact of the different Balassa stages in a GE analysis to evaluate four different Brexit scenarios, ranging from a soft Brexit to a very hard Brexit. The latter scenario leads to a $32 \%$ decrease in real exports and a $0.8 \%$ decrease in real GDP for the UK. Other EU members also lose from Brexit, especially Ireland and small open economies like the Netherlands. Non-EU members actually gain from Brexit due to trade diversion effects. Similarly, to Brexit I investigate the impact of TTIP and CETA on both the participating countries and non-participating countries. TTIP has a substantial effect on both the US and the EU, while CETA has a much smaller and insignificant effect.

In future research the GABI index can be extended including more countries and economic integration agreements. Another improvement is to find a more objective way to establish the weighting of different economic integration events. 


\section{References}

Anderson, James E. 1979. A Theoretical Foundation for the Gravity Equation. The American Economic Review, 69(1), pp. 106-116.

Anderson, James E., \& van Wincoop, Eric. 2003. Gravity with Gravitas: A Solution to the Border Puzzle. The American Economic Review, 93(1), pp. 170-192.

Anderson, James E., \& van Wincoop, Eric. 2004. Trade Costs. Journal of Economic Literature, 42(3), pp. 691-751.

Anderson, James E., Larch, Mario, \& Yotov, Yoto V. 2015. Estimating General Equilibrium Trade Policy Effects: GE PPML. Tech. rept.

Arvis, Jean-François, \& Shepherd, Ben. 2013. The Poisson quasi-maximum likelihood estimator: a solution to the 'adding up' problem in gravity models. Applied Economics Letters, 20(6), pp. 515-519.

Badinger, Harald. 2005. Growth Effects of Economic Integration: Evidence from the EU Member States. Review of World Economics, 141(1), pp. 50-78.

Badinger, Harald. 2008. Technology- and investment-led growth effects of economic integration: a panel cointegration analysis for the EU-15 (1960 - 2000). Applied Economics Letters, 15(7), pp. 557-561.

Baier, Scott L., \& Bergstrand, Jeffrey H. 2007. Do free trade agreements actually increase members' international trade? Journal of International Economics, 71(1), pp. $72-95$.

Baier, Scott L., Bergstrand, Jeffrey H., \& Feng, Michael. 2014. Economic integration agreements and the margins of international trade. Journal of International Economics, 93(2), pp. 339-350.

Balassa, Béla A. 1961. The theory of economic integration. Irwin series in economics. R.D. Irwin.

Baldwin, Richard, \& Wyplosz, Charles. 2015. The Economics of European Integration. 5th edn. McGraw-Hill Higher Education.

Bergstrand, Jeffrey H. 1985. The Gravity Equation in International Trade: Some Microeconomic Foundations and Empirical Evidence. The Review of Economics and Statistics, 67(3), pp. 474-481. 
Bergstrand, Jeffrey H., Larch, Mario, \& Yotov, Yoto V. 2015. Economic integration agreements, border effects, and distance elasticities in the gravity equation. European Economic Review, 78, pp. 307-327.

Brainard, S. Lael. 1997. An Empirical Assessment of the Proximity-Concentration Trade-off Between Multinational Sales and Trade. The American Economic Review, 87(4), pp. 520-544.

Bun, Maurice J. G., \& Klaassen, Franc J. G. M. 2007. The Euro Effect on Trade is not as Large as Commonly Thought. Oxford Bulletin of Economics and Statistics, 69(4), pp. $473-496$.

Cipollina, Maria, \& Salvatici, Luca. 2010. Reciprocal Trade Agreements in Gravity Models: A Meta-Analysis. Review of International Economics, 18(1), pp. 63-80.

Dorrucci, Ettore, Fratzscher, Marcel, Mongelli, Francesco P., \& Firpo, Stefano. 2002 (Oct.). European Integration: what lessons for other regions? The case of Latin America. Working Paper Series. European Central Bank.

Dorrucci, Ettore, Firpo, Stefano, Fratzscher, Marcel, \& Mongelli, Francesco Paolo. 2005. The Path of European Institutional and Economic Integration: What Lessons for Latin America? Journal of Economic Integration, 20(2), pp. 217-251.

Dorrucci, Ettore, Ioannou, Demosthenes, Mongelli, Francesco, \& Terzi, Alessio. 2015. The four unions "PIE" on the Monetary Union "CHERRY": a new index of European Institutional Integration. Occasional Paper Series 160. European Central Bank.

Dür, Andreas, Baccini, Leonardo, \& Elsig, Manfred. 2014. The design of international trade agreements: Introducing a new dataset. The Review of International Organizations, $\mathbf{9}(3)$, pp. 353-375.

Egger, Peter. 2000. A note on the proper econometric specification of the gravity equation. Economics Letters, 66(1), pp. 25-31.

Egger, Peter, \& Larch, Mario. 2012. Estimating Consistent Border Effects in Gravity Models with Multilateral Resistance. The World Economy, 35(9), pp. 1121-1125.

Egger, Peter, \& Tarlea, Filip. 2017. Comparing Apples to Apples: Estimating Consistent Partial Effects of Preferential Economic Integration Agreements. CEPR Discussion Papers 11894. C.E.P.R. Discussion Papers.

Fally, Thibault. 2015. Structural gravity and fixed effects. Journal of International Economics, 97(1), pp. 76-85. 
Frankel, Jeffrey A. 1997. Regional Trading Blocs in the World Economic System. Peterson Institute Press: All Books, no. 72. Peterson Institute for International Economics.

Head, Keith, \& Mayer, Thierry. 2014. Gravity Equations: Workhorse,Toolkit, and Cookbook. Handbook of International Economics, vol. 4. Elsevier. Chap. 3, pages pp. 131-195.

Heckscher, Eli. 1919. The Effects of Foreign Trade on the Distribution of Income. Ekonomisk Tidskrift, 21, pp. 497-512.

Helpman, Elhanan, Melitz, Marc J., \& Yeaple, Stephen R. 2004. Export Versus FDI with Heterogeneous Firms. The American Economic Review, 94(1), pp. 300-316.

Klaassen, Franc, \& Teulings, Rutger. 2015a. Untangling Multilateral Boundaries. Working Paper. University of Amsterdam.

Klaassen, Franc J. G. M., \& Teulings, Rutger. 2015b (December 24). Untangling Fixed Effects and Constant Regressors. Tech. rept. 15-137/VI. Tinbergen Institute Discussion Paper.

Krugman, Paul R. 1979. Increasing returns, monopolistic competition, and international trade. Journal of International Economics, 9(4), pp. 469 - 479.

Krugman, Paul R. 1980. Scale Economies, Product Differentiation, and the Pattern of Trade. The American Economic Review, 70(5), pp. 950-959.

Melitz, Marc J. 2003. The Impact of Trade on Intra-Industry Reallocations and Aggregate Industry Productivity. Econometrica, 71(6), pp. 1695-1725.

Mundell, Robert A. 1961. A Theory of Optimum Currency Areas. The American Economic Review, 51(4), 657-665.

Newey, Whitney K., \& West, Kenneth D. 1987. A Simple, Positive Semi-definite, Heteroskedasticity and Autocorrelation Consistent Covariance Matrix. Econometrica, 55(3), pp. 703-708.

Newey, Whitney K., \& West, Kenneth D. 1994. Automatic Lag Selection in Covariance Matrix Estimation. Review of Economic Studies, 61(4), pp. 631-653.

Ohlin, Bertil. 1933. Interregional and international trade. Harvard University Press.

Redding, Stephen J. 2011. Theories of Heterogeneous Firms and Trade. Annual Review of Economics, 3(1), pp. 77-105. 
Rivera-Batiz, Luis A., \& Romer, Paul M. 1991. Economic Integration and Endogenous Growth. The Quarterly Journal of Economics, 106(2), pp. 531-555.

Roy, Jayjit. 2010. Do Customs Union Members Engage in More Bilateral Trade than Free-Trade Agreement Members? Review of International Economics, 18(4), pp. 663-681.

Santos-Silva, João M. C., \& Tenreyro, Silvana. 2006. The Log of Gravity. The Review of Economics and Statistics, 88(4), pp. 641-658.

Tinbergen, J. 1962. Shaping the World Economy; Suggestions for an International Economic Policy. Twentieth Century Fund, New York.

Viner, Jacob. 1950. The customs union issue. Studies in the administration of international law and organization. Carnegie Endowment for International Peace. 


\section{A General equilibrium analysis in the nominal model}

Start with the nominal gravity model ${ }^{15}$ satisfying the following conditions

$$
\begin{aligned}
X_{i j t}^{j} & =w_{i t}^{y}\left(\frac{b_{i j t} / S_{i j t}}{\Pi_{i t} P_{j t}}\right)^{1-\sigma} E_{j t} \\
\Pi_{i t} & =\left(\sum_{j}\left(\frac{b_{i j t} / S_{i j t}}{P_{j t}}\right)^{1-\sigma} w_{j}^{e}\right)^{\frac{1}{1-\sigma}}, \\
P_{j t} & =\left(\sum_{i}\left(\frac{b_{i j t} / S_{i j t}}{\Pi_{i t}}\right)^{1-\sigma} w_{i}^{y}\right)^{\frac{1}{1-\sigma}} \\
Y_{i t} & =\sum_{j} X_{i j t}=p_{i t} Q_{i t} \\
p_{i t} & =\left(\frac{w_{i t}^{y}}{\lambda_{i t}}\right)^{\frac{1}{1-\sigma}} \frac{1}{\Pi_{i t}} \\
Y_{i t} & =\phi_{i t} E_{i t},
\end{aligned}
$$

where $p_{i t}$ is the equilibrium price, $w_{i t}^{y}=\frac{Y_{i t}}{Y_{W t}}$ and $w_{j t}^{e}=\frac{E_{j t}}{E_{W t}}$ (realize that $Y_{W t}=E_{W t}$ ), $Q_{i t}$ is the total output of good $i$ by country $i$ at time $t$ (where $Q_{i t}=\sum_{i} x_{i j t}$ ) and $\phi_{i t}$ is an exogenous parameter allowing for unbalanced trade of country $i$ at time $t$, as proposed by Anderson et al. (2015). I assume that $\lambda_{i t}, S_{i j t}, Y_{W t}$ and $Q_{i t}$ are exogenous and do not change if $b_{i j t}$ changes. Realize that $S_{i j t}=S_{i U S t} S_{U S j t}$.

Besides (A.1)-(A.3), which are already presented in Section 3.1, we have three additional underlying equations. First, (A.4) is the market clearing condition. This helps us to derive (A.5), the equilibrium price. Finally, (A.6) is the balanced trade condition, where $\phi_{i t}$ allows for imbalanced trade.

So, in total I have six unknown variables that change when the trade barrier changes: $X_{i j t}^{j}, Y_{i t}, E_{j t}, \Pi_{i t}, P_{j t}$ and $p_{i t}$. To solve for these six unknowns Anderson et al. (2015) developed the following iteration procedure based on (A.1)-(A.6).

\footnotetext{
${ }^{15}$ This section is in addition to Section 3.1.
} 


\section{A.1 Estimate baseline model}

In the first step, I derive expenditure and income using the market clearance conditions (A.4) and use these two variables and (A.6) to derive $\phi_{i t}$

$$
\begin{aligned}
Y_{i t}^{b} & =\sum_{j} E x p_{i j t}^{i}, \\
E_{j t}^{b} & =\sum_{i} E_{x p}^{j} p_{i j t}, \\
\phi_{i t} & =\frac{Y_{i t}}{E_{i t}},
\end{aligned}
$$

where the $b$ in the superscript indicates that these variables are stemming from the baseline case.

Next, I estimate the baseline model, where I normalize $\theta_{S W t}^{m}$ and both $\alpha_{i j}$ and $\tau_{i j}$ for $i=S W$ and $j=S W$ to zero,

$$
\operatorname{Exp}_{i j t}^{j}=\exp \left(t_{i j t}^{b \prime} \beta+\alpha_{i j}+\tau_{i j t} \cdot t+\theta_{i t}^{x}+\theta_{j t}^{m}\right) \eta_{i j t}
$$

and construct $\widehat{\operatorname{Exp}}_{i j t}^{j, b}$.

I use these estimation results together with (A.1) to derive the multilateral resistance (MR) terms $\Pi_{i t}$ and $P_{j t}$ using the estimated country-time FE with the following expressions

$$
\begin{aligned}
\widehat{\Pi}_{i t}^{(1-\sigma), b} & =\frac{Y_{i t}^{b}}{\exp \left(\hat{\theta}_{i t}^{x}\right)} E_{S W t}^{b}, \\
\widehat{P}_{j t}^{(1-\sigma), b} & =\frac{E_{j t}^{b}}{\exp \left(\hat{\theta}_{j t}^{m}\right)} \frac{1}{E_{S W t}^{b}},
\end{aligned}
$$

where $E_{S W t}$ stems from the normalization. Note that $S_{i U S t}^{1-\sigma}, S_{U S j t}^{1-\sigma}$ and $Y_{W t}$ all drop out in the ratio of change because they are assumed exogenous, so I omit them.

Finally, I construct the baseline trade barrier

$$
\widehat{b}_{i j t}^{(1-\sigma), b}=\exp \left(t_{i j t}^{b \prime} \hat{\beta}+\hat{\alpha}_{i j}+\hat{\tau}_{i j} \cdot t\right)
$$

\section{A.2 Construct counterfactual}

In the second step I construct the counterfactual trade cost $\widehat{b}_{i j t}^{(1-\sigma), c}$ with (A.11), where I replace $t_{i j t}^{b}$ for $t_{i j t}^{c}$. The $c$ in the superscript indicates that this variable is stemming from the counterfactual case. 


\section{A.3 Estimate partial and conditional effect}

In the third step I estimate the partial effect and the effect conditional on output and expenditure being fixed.

\section{A.3.1 Partial effect}

The partial effect is estimate using (A.1)

$$
\widehat{\operatorname{Exp}}_{i j t}^{p}=Y_{i t}^{b}\left(\frac{\widehat{b}_{i j t}^{c}}{\widehat{\Pi}_{i t}^{b} \widehat{P}_{j t}^{b}}\right)^{1-\sigma} E_{j t}^{b},
$$

where the $p$ indicates that this estimate is stemming from the partial case. Note that $Y_{W t}$ and $S_{i j t}$ drop out when we calculate percentage change so we omit them here.

\section{A.3.2 Conditional effect}

Next I allow the multilateral resistance terms to change while keeping expenditure and income fixed, the conditional effect.

I estimate the following model, while keeping $\widehat{b}_{i j t}^{(1-\sigma), c}$ fixed,

$$
\operatorname{Exp}_{i j t}^{j}=\widehat{b}_{i j t}^{(1-\sigma), c} \exp \left(\theta_{i t}^{x}+\theta_{j t}^{m}\right) \eta_{i j t}
$$

and construct $\widehat{\operatorname{Exp}} \widehat{i j t}^{j, c n d}$, where $c n d$ indicates that this estimate stems from the conditional effect.

Next, I rederive the MR terms $\widehat{\Pi}_{i t}^{(1-\sigma), \text { cnd }}$ and $\widehat{P}_{j t}^{(1-\sigma), \text { cnd }}$ using the estimated countrytime FE and (A.9)-(A.10), respectively.

\section{A.4 Estimate full endowment effect}

In the fourth step I derive the full endowment case, allowing output and expenditure to change as well, with an iteration procedure.

Therefore, I first need to construct the equilibrium price ratio as a starting value for the iteration based on the expression for equilibrium prices (A.5):

$$
\begin{aligned}
\frac{\widehat{p_{i t}^{c n d}}}{p_{i t}^{b}} & =\left(\frac{\exp \left(\hat{\theta}_{i t}^{x, c n d}\right)}{\exp \left(\hat{\theta}_{i t}^{x, b}\right)} \frac{E_{S W t}^{b}}{E_{S W t}^{c n d}}\right)^{\frac{1}{1-\sigma}}, \\
\frac{\widehat{p_{j t}^{c n d}}}{p_{j t}^{b}} & =\left(\frac{\exp \left(\hat{\theta}_{j t}^{x, c n d}\right)}{\exp \left(\hat{\theta}_{j t}^{x, b}\right)} \frac{E_{S W t}^{b}}{E_{S W t}^{c n d}}\right)^{\frac{1}{1-\sigma}} .
\end{aligned}
$$


Note that $E_{S W t}^{c n d}=E_{S W t}^{b}$, so the expenditure ratio equals one. However, when I start updating prices expenditure will start changing and therefore this ratio as well. Furthermore, I will also use $\widehat{\operatorname{Exp}}_{i j t}^{f u l l(1)}=\widehat{\operatorname{Exp}}_{i j t}^{\text {cnd }}, \hat{\theta}_{i t}^{x, f u l l(2)}=\hat{\theta}_{i t}^{x, f u l l(1)}=\hat{\theta}_{i t}^{x, \text { cnd }}, \theta_{j t}^{m, f u l l(2)}=$ $\theta_{j t}^{m, f u l l(1)}=\theta_{j t}^{m, \text { cnd }}$ and the ratios $\left(\frac{\widehat{\Pi}_{i t}^{\text {full }(1)}}{\widehat{\Pi}_{i t}^{\text {full }(2)}}\right)^{1-\sigma}=\left(\frac{\widehat{\Pi}_{i t}^{\text {cnd }}}{\widehat{\Pi}_{i t}^{\text {chd }}}\right)^{1-\sigma}$ and $\left(\frac{\widehat{P}_{j t}^{\text {full(1) }}}{\widehat{P}_{j t}^{\text {full }(2)}}\right)^{1-\sigma}=$ $\left(\frac{\widehat{P}_{j t}^{c n d}}{\widehat{P}_{j t}^{c n d}}\right)^{1-\sigma}$ as starting values. The full superscript indicates that these variables stem from the full endowment GE analysis, where the numbers between bracket indicate the iteration step.

\section{A.4.1 Iterate to obtain full endowment effect}

I start by updating the export variable with the following expression derived from (A.1)

$$
\widetilde{\operatorname{Exp}} p_{i j t}^{j, f u l l(2)}=\frac{\widehat{p_{i t}^{\text {full }(2)}}}{p_{i t}^{\text {full }(1)}} \frac{\widehat{p_{j t}^{\text {full }(2)}}}{p_{j t}^{\text {full(1) }}}\left(\frac{\widehat{\Pi}_{i t}^{\text {full }(1)}}{\widehat{\Pi}_{i t}^{\text {full(2)}}} \frac{\widehat{P}_{j t}^{\text {full }(1)}}{\widehat{P}_{j t}^{\text {full }(2)}}\right)^{1-\sigma} \widehat{\operatorname{Exp}} \widehat{p}_{i j t}^{j, f u l l(1)},
$$

where I use that $Y_{i t}=p_{i t} Q_{i t}$ and, taking ratios, I get $\frac{\widehat{Y}_{i t}^{\text {full }(2)}}{\widehat{Y}_{i t}^{\text {full }(1)}}=\frac{\widehat{p_{i t}^{f u l l(2)}}}{p_{i t}^{\text {full }(1)}}$ under the assumption that $Q_{i t}$ is exogenous. ${ }^{16}$ Note that $\widetilde{\operatorname{Exp}}_{i j t}^{j, f u l l(2)}$ has a tilde to distinguish it from estimated export flows.

I use the newly generated export flows and the counterfactual trade cost to estimate

$$
\widetilde{\operatorname{Exp}}_{i j t}^{j, f u l l(2)}=b_{i j t}^{(1-\sigma), c} \exp \left(\theta_{i t}^{x, f u l l(3)}+\theta_{j t}^{m, f u l l(3)}\right) \varepsilon_{i j t}
$$

and construct $\widehat{\operatorname{Exp}}_{i j t}^{j, f u l l(2)}$.

Next, the predicted export flows can be used to derive income

$$
\widehat{Y}_{i t}^{f u l l(3)}=\sum_{j} \widehat{\operatorname{Exp}}_{i j t}^{j, f u l l(2)}
$$

Consequently, expenditure $\widehat{E}_{j t}^{\text {full(3) }}$ follows from (A.6). I use the estimate exporter-time

\footnotetext{
${ }^{16}$ Note that $Y_{i t}=p_{i t} Q_{i t}$ seem to contradict each other $Y_{i t}=\sum_{j} X_{i j t}=\sum_{j} b_{i j t} p_{i t} x_{i j t}$, because the latter shows that $Y_{i t}$ depends on $b_{i j t}$ as well. The intuition behind this is that there is a transport sector that contributes to the income of country $i$; this is different from the iceberg trade cost that is standard in the literature. So to make these two definitions in line with each other we have to adjust the former to $Y_{i t}=p_{i t} Q_{i t} \sum_{j} b_{i j t} \frac{x_{i j t}}{Q_{i t}}$. The problem of this expression is that it depends on real export. This leads to two problems. First, real export is hard to obtain in general because we need to agree upon the appropriate deflator to deflate nominal export flows. Second, if we have agreed upon an appropriate deflator, say the exporter price index, we have to update the exporter price index with changing equilibrium prices, complicating the GE analysis further. Solving this problem I leave for future research.
} 
and importer-time FE and (A.14) to derive the new equilibrium price ratios $\frac{\widehat{p_{i t}^{\text {full }(3)}}}{p_{i t}^{\text {full }(2)}}$ and $\frac{\widehat{p_{j t}^{\text {full }(3)}}}{p_{j t}^{\text {full(2)}}}$. Finally, I construct the new MR terms using the estimated $\hat{\theta}_{i t}^{x, \text { full }(3)}$ and $\hat{\theta}_{j t}^{m, f u l l(3)}$, output $\widehat{Y}_{i t}^{\text {full( (3) }}$, expenditure $\widehat{E}_{j t}^{\text {full(3) }}$ and (A.9)-(A.10).

I iterate this process until the equilibrium price ratio $\frac{\widehat{p_{i t}^{\text {full }(3)}}}{p_{i t}^{\text {full }(2)}}$ does not change anymore.

\section{A.5 Derive full endowment GE effect}

In the fifth and final step I derive the final equilibrium price ratio $\frac{\widehat{p_{i t}^{f u l l}}}{p_{i t}^{b}}$ using (A.14). I use this ratio to generate income

$$
\widehat{Y}_{i t}^{f u l l}=\frac{\widehat{p_{i t}^{f u l l}}}{p_{i t}^{b}} Y_{i t}^{b}
$$

and consequently expenditure $\widehat{E}_{j t}^{f u l l}$ is constructed using (A.6). Next, the MR terms are constructed using the estimated $\hat{\theta}_{i t}^{x, f u l l}$ and $\hat{\theta}_{j t}^{m, f u l l}$, output $\widehat{Y}_{i t}^{\text {full }}$, expenditure $\widehat{E}_{j t}^{\text {full }}$ and (A.9)-(A.10).

Finally, I construct the new export flows based on (A.1)

$$
\widehat{E x p}_{i j t}^{j, f u l l}=\widehat{Y}_{i t}^{\text {full }}\left(\frac{\widehat{b}_{i j t}^{c}}{\widehat{\Pi}_{i t}^{\text {full }} \widehat{P}_{j t}^{f u l l}}\right)^{1-\sigma} \widehat{E}_{j t}^{\text {full }} .
$$

Now I can derive the percentage change in the full endowment GE with respect to the baseline scenario as a consequence of a change in the counterfactual trade barrier. Using the percentage change in the price ratio $\frac{\widehat{p_{i t}^{\text {ful }}}}{p_{i t}^{b}}$ and the percentage change of $\widehat{P}_{j t}^{\text {full }}$ I can also calculate the percentage change of full real GDP by

$$
\frac{d \widehat{y}_{i t}^{f u l l}}{\widehat{y}_{i t}^{b}}=d\left(\frac{\widehat{p_{i t}^{f u l l}}}{p_{i t}^{b}}\right)-\frac{d \widehat{P}_{j t}^{f u l l}}{\widehat{P}_{j t}^{b}},
$$

where $d \widehat{y}_{i t}^{f u l l}=\widehat{y}_{i t}^{f u l l}-\widehat{y}_{i t}^{b}$ and I use that $y_{i t}=\frac{Y_{i t}}{P_{i t}}$ implying that $\frac{d y_{i t}}{y_{i t}}=\frac{d Y_{i t}}{Y_{i t}}-\frac{d P_{i t}}{P_{i t}}$, where one has to realize that $Y_{i t}=p_{i t} Q_{i t}$ and $Q_{i t}$ is exogenous. 


\section{B General equilibrium analysis in the real model}

Start with the real gravity equation ${ }^{17}$ by Klaassen \& Teulings (2015a) satisfying the following equations

$$
\begin{aligned}
x_{i j t} & =\left(\frac{w_{i t}^{y}}{\lambda_{i t}}\right)^{\frac{-1}{1-\sigma}} w_{i t}^{y}\left(\frac{b_{i j t}}{s_{i j t} \pi_{i t}}\right)^{-\sigma} c_{j t}, \\
\pi_{i t} & =\left[\sum_{j}\left(\frac{b_{i j t}}{s_{i j t}}\right)^{1-\sigma} w_{j t}^{e}\right]^{\frac{1}{1-\sigma}}, \\
y_{i t} & =\sum_{j} x_{i j t}, \\
\frac{p_{i t}}{P_{i t}} & =\left(\frac{w_{i t}^{y}}{\lambda_{i t}}\right)^{\frac{1}{1-\sigma}} \frac{1}{\pi_{i t}} \\
c_{j t} & =\frac{1}{\phi_{j t}} \frac{p_{j t}}{P_{j t}} \psi_{j t} y_{j t}, \\
\psi_{j t} & =\sum_{i} b_{j i t} w_{j i t}^{x},
\end{aligned}
$$

where $\frac{p_{i} t}{P_{i} t}$ is the relative equilibrium price, $\frac{p_{j t}}{P_{j t}} \psi_{j t}$ is the terms of trade of country $j$ (an improvement increases the purchasing power of country $j$, while a deterioration decreases the purchasing power of country $j$ ), $w_{i t}^{y}=\frac{y_{i t}}{y_{W t}}, w_{j t}^{e}=\frac{c_{j t}}{c_{W t}}, w_{j i t}^{x}=\frac{x_{j i t}}{\sum_{i} x_{j i t}}$ (realize that $y_{W t}=c_{W t}$ ) and $\phi_{i t}$ is an exogenous parameter that allows for unbalanced trade in country $i$ at time $t$. I assume that $y_{i t}, y_{j t}, y_{W t}, s_{i j t}, \lambda_{i t}$ and $\lambda_{j t}$, are exogenous and do not change if $b_{i j t}$ changes.

Besides (B.1)-(B.2), which are already presented in Section 3.1, we have four additional underlying equations. First, (B.3) is the market clearing condition for quantity of goods. This helps us to derive (B.4), the relative equilibrium price. Third, (B.5) is the balanced trade condition, where $\phi_{i t}$ allows for imbalanced trade. Finally, (B.6) gives weighted bilateral trade cost.

So, in total I have five unknown variables that change when the trade barrier changes: $x_{i j t}, \frac{p_{i} t}{P_{i} t}, c_{j t}, \pi_{i t}$ and $\psi_{j t}$. If I substitute (B.4) into (B.5) and the resulting balanced trade expression into (B.1) and estimate the latter, I only have two unknowns remaining: $\pi_{i t}$ and $\psi_{j t}$. To solve for these final two unknowns I use a similar method as in Section A. However, because I have only two unknowns that are fully captured by the country-time FE, I no longer need to iterate; so there is no need to perform step four from the nominal GE analysis, as described in Section A.4. Instead I can now

\footnotetext{
${ }^{17}$ This section is in addition to Section 3.1.
} 
directly estimate the full endowment GE by taking the counterfactual trade barrier into account. Hence, for the real GE analysis I only need four steps.

\section{B.1 Estimate baseline model}

In step one I start by estimating the baseline model, where I normalize $\theta_{S W t}^{m}$ and both $\alpha_{i j}$ and $\tau_{i j}$ for $i=S W$ and $j=S W$ to zero,

$$
\exp _{i j t}=\exp \left(t_{i j t}^{b \prime} \beta+\alpha_{i j}+\tau_{i j t} \cdot t+\theta_{i t}^{x}+\theta_{j t}^{m}\right) \eta_{i j t}
$$

and construct $\widehat{\exp }_{i j t}^{b}$.

Next, I construct the baseline trade barrier

$$
\widehat{b}_{i j t}^{-\sigma, b}=\exp \left(t_{i j t}^{b \prime} \hat{\beta}+\hat{\alpha}_{i j}+\hat{\tau}_{i j} \cdot t\right)
$$

I use this baseline trade barrier to construct the export weighted trade barrier based on (B.6)

$$
\widehat{\psi}_{j t}^{b}=\sum_{i} \widehat{b}_{j i t}^{b} w_{j i t}^{x, b}
$$

where $w_{j i t}^{x, b}$ is constructed using $\exp _{i j t}$.

Finally, I derive the multilateral resistance terms $\pi_{i t}$ and $\pi_{j t}$ using the estimated country-time FE and (B.1) and (B.5), respectively, resulting in the following expression

$$
\begin{aligned}
\widehat{\pi}_{i t}^{-\sigma, b} & =\frac{1}{\exp \left(\hat{\theta}_{i t}^{x}\right)} \widehat{\psi}_{S W t}^{b}, \\
\widehat{\pi}_{j t}^{b} & =\frac{\widehat{\psi}_{j t}^{b}}{\exp \left(\hat{\theta}_{j t}^{m}\right)} \frac{1}{\widehat{\psi}_{S W t}^{b}},
\end{aligned}
$$

where $\widehat{\psi}_{S W t}^{b}$ is added due to the normalization. Note that $y_{i t}, y_{j t}, y_{W t}, s_{i U S t}, s_{U S j t}$, $\lambda_{i t}$ and $\lambda_{j t}$ all drop out when we look at ratio of change because they are exogenous.

\section{B.2 Construct counterfactual}

In the second step I construct the counterfactual trade barrier $\widehat{b}_{i j t}^{-\sigma, c}$ using (B.8), where I replace $t_{i j t}^{b \prime}$ by the counterfactual $t_{i j t}^{c \prime}$.

\section{B.3 Estimate partial and full effect}

In the third step I estimate the partial effect and the full endowment effect. 


\section{B.3.1 Partial effect}

The partial effect is estimate by (B.1), resulting into

$$
\widehat{\exp }_{i j t}^{p}=\left(\frac{\widehat{b}_{i j t}^{c}}{\widehat{\pi}_{i t}^{b}}\right)^{-\sigma} \frac{\widehat{\psi}_{j t}^{b}}{\widehat{\pi}_{j t}^{b}} .
$$

Note that $y_{i t}, y_{j t}, y_{W t}, s_{i j t}, \lambda_{i t}$ and $\lambda_{j t}$ drop out when we calculate percentage change so we omit them here.

\section{B.3.2 Full effect}

Now I allow $\pi_{i t}$ and $\pi_{j t}$ to change. I start by estimating the following model

$$
\exp _{i j t}=\widehat{b}_{i j t}^{-\sigma, c} \exp \left(\theta_{i t}^{x}+\theta_{j t}^{m}\right) \eta_{i j t}
$$

and construct $\widehat{\exp }_{i j t}^{f u l l}$. Note that $\widehat{b}_{i j t}^{-\sigma, c}$ is held fixed.

Next, I construct the weighted trade cost $\widehat{\psi}_{j t}^{\text {full }}$ using the counterfactual trade barrier $\widehat{b}_{j i t}^{c}$ and (B.9), where I use $\widehat{\exp }_{i j t}^{\text {full }}$ to construct the export weights. Finally, I derive the multilateral resistance terms $\widehat{\pi}_{i t}$ and $\widehat{\pi}_{i t}$ using the estimated country-time FE, $\widehat{\psi}_{j t}^{\text {full }}$ and (B.10)-(B.11).

\section{B.4 Derive full endowment GE effect}

In the fourth and final step I use the full endowment GE from Section B.3.2 to derive the percentage change with respect to the baseline scenario from Section B.1 as a consequence of the change in the counterfactual trade barrier.

\section{Additional tables}


Table C.1: FTA starting dates and participating-countries for the FTA variable $F T A_{i j t}^{B B}$.

\begin{tabular}{lll}
\hline \hline FTA name & Start & Participating countries \\
\hline European Union (EU) & 1958 & $\begin{array}{l}\text { Austria (1995), Denmark (1973), Finland (1995), France, } \\
\text { Germany, Greece (1981), Ireland (1973), Italy, Netherlands, }\end{array}$ \\
& & $\begin{array}{l}\text { Portugal (1986), Spain (1986), Sweden (1995), United Kingdom (1973) } \\
\text { Austria (until 1995), Denmark (until 1973), }\end{array}$ \\
$\begin{array}{l}\text { European Free Trade } \\
\text { Association (EFTA) }\end{array}$ & 1960 & $\begin{array}{l}\text { Finland (1986-1995), Portugal (until 1986), Sweden (until 1995), } \\
\text { United Kingdom (Until 1973), Norway, Switzerland }\end{array}$ \\
EU-EFTA & 1973 & $\begin{array}{l}\text { Agreement between all EU and EFTA members } \\
\text { Finland enters in 1974 as associate EFTA member }\end{array}$ \\
CUSFTA & 1989 & $\begin{array}{l}\text { United States and Canada } \\
\text { New agreement between all EU and EFTA members }\end{array}$ \\
$\begin{array}{l}\text { European Economic Area (EEA) } \\
\text { North American Free }\end{array}$ & 1994 & $\begin{array}{l}\text { United States, Canada } \\
\text { Trade Agreement (NAFTA) }\end{array}$ \\
\hline \hline
\end{tabular}

Number between brackets are entry or exit dates of individual countries. 




